\title{
Extrapolating regional probability of drying of headwater streams using discrete observations and gauging networks
}

\author{
Aurélien Beaufort, Nicolas Lamouroux, Hervé Pella, Thibault Datry, and Eric Sauquet \\ Irstea, UR RiverLy, centre de Lyon-Villeurbanne, 5 rue de la Doua CS 20244, 69625 Villeurbanne, France \\ Correspondence: Aurélien Beaufort (aurelien.beaufort@irstea.fr)
}

Received: 9 November 2017 - Discussion started: 15 November 2017

Revised: 23 March 2018 - Accepted: 29 April 2018 - Published: 24 May 2018

\begin{abstract}
Headwater streams represent a substantial proportion of river systems and many of them have intermittent flows due to their upstream position in the network. These intermittent rivers and ephemeral streams have recently seen a marked increase in interest, especially to assess the impact of drying on aquatic ecosystems. The objective of this paper is to quantify how discrete (in space and time) field observations of flow intermittence help to extrapolate over time the daily probability of drying (defined at the regional scale). Two empirical models based on linear or logistic regressions have been developed to predict the daily probability of intermittence at the regional scale across France. Explanatory variables were derived from available daily discharge and groundwater-level data of a dense gauging/piezometer network, and models were calibrated using discrete series of field observations of flow intermittence. The robustness of the models was tested using an independent, dense regional dataset of intermittence observations and observations of the year 2017 excluded from the calibration. The resulting models were used to extrapolate the daily regional probability of drying in France: (i) over the period 2011-2017 to identify the regions most affected by flow intermittence; (ii) over the period 1989-2017, using a reduced input dataset, to analyse temporal variability of flow intermittence at the national level. The two empirical regression models performed equally well between 2011 and 2017. The accuracy of predictions depended on the number of continuous gauging/piezometer stations and intermittence observations available to calibrate the regressions. Regions with the highest performance were located in sedimentary plains, where the monitoring network was dense and where the regional probability of drying was the highest. Conversely, the worst performances were obtained in mountainous regions. Finally, tem-
\end{abstract}

poral projections (1989-2016) suggested the highest probabilities of intermittence (> 35\%) in 1989-1991, 2003 and 2005. A high density of intermittence observations improved the information provided by gauging stations and piezometers to extrapolate the temporal variability of intermittent rivers and ephemeral streams.

\section{Introduction}

Headwater streams represent a substantial proportion of river systems (Leopold et al., 1964; Nadeau and Rains, 2007; Benstead and Leigh, 2012). From an ecological point of view, headwater catchments are at the interface between terrestrial and aquatic ecosystems and they often harbour a unique biodiversity with a very high spatial turnover (Meyer et al., 2007; Clarke et al., 2008; Finn et al., 2011). Their contribution to the functioning of hydrographic networks is essential: sediment flows, inputs of particulate organic matter and nutrients, refugia/colonisation, sources of aquatic organisms (Meyer et al., 2007; Finn et al., 2011).

Headwater streams are generally naturally prone to flow intermittence, i.e. streams which stop flowing or dry up at some point in time and space, mainly due to their upstream position in the network and their high reactivity to natural or human disturbances (Benda et al., 2005; Datry et al., 2014b). These waterways which cease flow and/or dry are referred to as intermittent rivers and ephemeral streams (IRES). The geographic extent of IRES is poorly documented due to mapping limitations (digital elevation models, satellite images, aerial photos) and because of their size and their location (Leopold et al., 1994; Nadeau and Rains, 2007; Benstead and Leigh, 2012; Fritz et al., 2013). However, the proportion of 
IRES in hydrological networks can be very large: for example, they represent $60 \%$ of the length of rivers in the United States (Nadeau and Rains, 2007) and are considered to represent probably more than $50 \%$ of the global hydrological network (Larned et al., 2010; Datry et al., 2014b). Considering only gauging stations with continuous records may lead to severe underestimation of their regional extent (Snelder et al., 2013; De Girolamo et al., 2015; Eng et al., 2016).

Recently, IRES have seen a marked increase in interest stimulated by the challenges of water management facing the global change context (water scarcity issues, climate change impact, etc.) (Acuña et al., 2014; Datry et al., 2016b). Studies have characterised the hydrological functioning of IRES (Gallart et al., 2012; Costigan et al., 2016; Sarremejane et al., 2017) to assess the effects of flow intermittence on aquatic ecosystems (Larned et al., 2010; Datry et al., 2016b; Leigh et al., 2016; Leigh and Datry, 2017). IRES have been altered due to human actions (abstraction, hill dams, low-water support, pollution, etc.) despite their high and unique biodiversity (Datry et al., 2014a; Garcia et al., 2017a). In addition, some perennial streams are becoming intermittent due to global change, water abstraction or river damming (Skoulikidis, 2009), and the extent of IRES may increase in the future (Döll and Schmied, 2012; Jaeger et al., 2014; Pumo et al., 2016; Garcia et al., 2017b; De Girolamo et al., 2017a).

A better hydrological understanding of IRES is now essential and improved management requires knowledge of both the spatial extent and arrangement of IRES within the river network (Boulton, 2014; Acuña et al., 2017). Efforts have been made to estimate the spatial distribution of IRES at the catchment scale (Skoulikidis et al., 2011; Datry et al., 2016a), at the regional scale (Gómez et al., 2005) and at the national scale (Snelder et al., 2013). In France, Snelder et al. (2013) suggested a classification of IRES regimes and spatialised their distribution. Based on an analysis of the continuous gauging network, they showed that the proportion of IRES accounted for 20 to $39 \%$ of the hydrographic network. The accuracy of the obtained map is highly dependent on the density of the flow monitoring network. The installation of additional gauging stations is expensive and headwater systems may be difficult to monitor due to active geomorphology processes or to difficult access.

As a promising tool to advance the mapping of IRES, citizen science creates opportunities to overcome the lack of hydrological data, contributes to densifying the flow-state observation network (Turner and Richter, 2011; Buytaert et al., 2014; Datry et al., 2016b) and could be used for hydrological model calibration (van Meerveld et al., 2017). In France, Datry et al. (2016a) used such data to describe the spatio-temporal dynamics of aquatic and terrestrial habitats within five river catchments located in the western part of France. They showed that processes resulting in flow intermittence were complex at a fine scale and could vary substantially among nearby catchments. However, these data were only available in a few catchments, limiting any at- tempt to map large-scale patterns of flow intermittence in river networks. Since this first attempt, new sources of observational data have become available in France thanks to the ONDE network (Observatoire National des Etiages, https: //onde.eaufrance.fr, last access: 22 May 2018). This unique network in Europe provides frequent discrete field observations (five inspections per year) of the flow intermittence across more than 3300 sites throughout France and located mostly in headwater areas.

However, discrete observations of intermittence do not provide any information on the persistence of dry conditions between two consecutive dates of observation. The rewetting-drying events could have significant impacts on communities whose survival is conditioned by the duration/frequency of drying. The duration of drying is of importance for ecologists, as one key driver for the composition and persistence of aquatic species (Vardakas et al., 2017; Kelso and Entrekin, 2018; Vadher et al., 2018). Temporal extrapolations of river flow regimes are thus necessary to summarise the different facets of flow intermittence at various timescales, from daily to inter-annual.

The main objective of this paper is to use discrete (in space and time) field observations of flow intermittence to extrapolate over time the daily probability of drying (averaged at the regional scale). We first carried out a quantitative analysis of the ONDE network data in order to characterise the information that they contribute in comparison with the data resulting from the conventional hydrological monitoring. Then, we developed two empirical models based on linear or logistic regressions to convert discontinuous series of flow intermittence observation from ONDE into continuous daily probability of drying, defined at the regional scale across France. Explanatory variables were derived from available continuous daily discharge and groundwater-level data of a dense gauging/piezometer network, and models were calibrated using the ONDE discrete observations. The robustness of the models was tested using (1) an independent, dense regional dataset of intermittence observations and (2) observations of the year 2017 excluded from the calibration. Finally, the resulting models were used to extrapolate the regional probability of drying in France: (i) over the period 2012-2017 to identify the regions most affected by flow intermittence; (ii) over the period 1989-2017, using a reduced input dataset, to analyse temporal variability of flow intermittence at the national level.

\section{Material and methods}

\subsection{Study area}

The study area is continental France and Corsica $\left(550000 \mathrm{~km}^{2}\right)$. France is located in a temperate zone characterised by a variety of climates due to the influences 
of the Atlantic Ocean, the Mediterranean Sea and mountain areas.

We defined regions as combinations of "level-2 HydroEcoRegions" (HER2) and classes of hydrological regimes (HR). Hydro-EcoRegion (HER) corresponds to a typology developed for river management in accordance with the European Water Framework Directive. The Hydro-EcoRegion classification includes 22 "level-1 Hydro-EcoRegions" (HER1) based on geology, topography and climate, and considered the primary determinants of the functioning of water ecosystems (Wasson et al., 2002). HER2 correspond to a finer classification accounting for stream size. HER2 have a mean drainage area of $5000 \mathrm{~km}^{2}$ (between 100 and $27000 \mathrm{~km}^{2}$ ). The hydrological regime classes (HR) were identified by reference to the work carried out by Sauquet et al. (2008) where it was possible to distinguish rainfallfed regimes, transition and snowmelt-fed river flow regimes. Overall, we used 280 regions (that is, HER2-HR combinations) with a mean drainage area of $1400 \mathrm{~km}^{2}$ (between 4 and $20000 \mathrm{~km}^{2}$ ).

\subsection{ONDE dataset discrete national flow-state observations}

The ONDE network was set up in 2012 by the French Biodiversity Agency (AFB, formerly ONEMA) with the aim of constituting a perennial network recording summer low-flow levels and used to anticipate and manage water crisis during severe drought events (Nowak and Durozoi, 2012).

There are 3300 ONDE sites distributed throughout France (Fig. 1). ONDE sites are located on headwater streams with a Strahler order of strictly less than 5 and balanced across HER2 regions to take into account the representativeness of the hydrological contexts (Nowak and Durozoi, 2012). The ONDE network is stable over time. Observations have been made monthly (around the 25th) by trained AFB staff, between April and September, every year since 2012. One of the statuses is assigned at each observation among "visible flow", "no visible flow" and "dried out". Here, we consider two intermittency statuses: "Flowing" when there is visible flow across the channel ("visible flow") and "Drying" when the channel is entirely devoid of surface water ("dried out") or when there is still water in the river bed but without visible flow (disconnected pools, lentic systems) ("no visible flow"). The proportion of drying sites determined on the basis of the ONDE network for each HER2-HR combination is considered a good estimate of the daily regional probability of drying $\left(\mathrm{RPoD}_{\mathrm{ONDE}}\right)$ of streams with a Strahler order of less than 5. Observed values of $\mathrm{RPoD}_{\text {onde }}$ are calculated as follows:

$\operatorname{RPoD}_{\mathrm{ONDE}}(d)=\frac{\left(N_{\text {drying }}\right)_{\mathrm{HER} 2-\mathrm{HR}}}{\left(N_{\text {flowing }}+N_{\text {drying }}\right)_{\mathrm{HER} 2-\mathrm{HR}}}$,

where $d$ denotes the observation date of the ONDE network, $N_{\text {drying }}$ and $N_{\text {flowing }}$ are the number of drying and of flowing

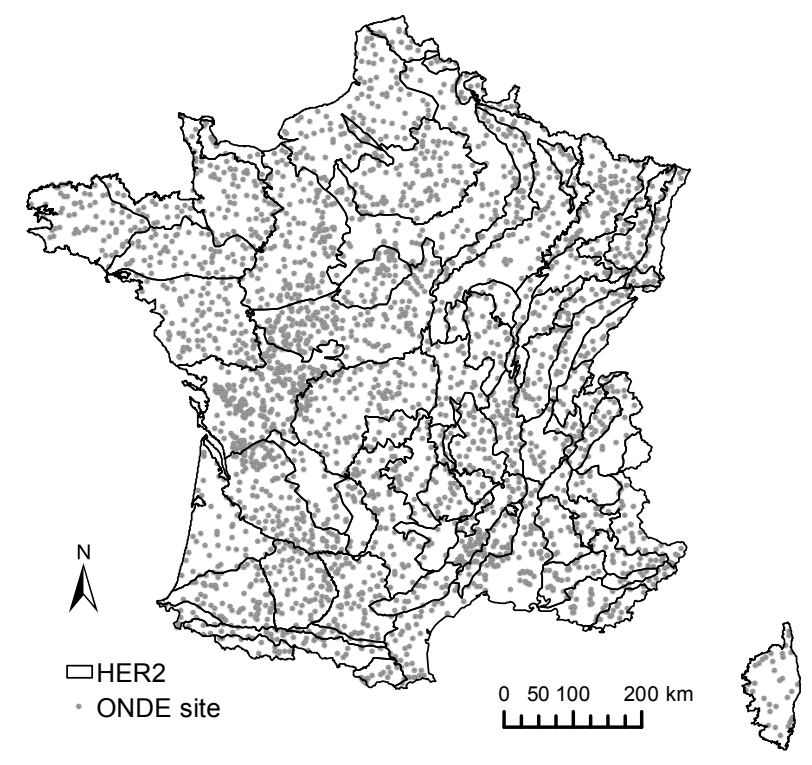

Figure 1. Location of the 3300 ONDE sites and partition into HER2.

statuses observed at ONDE sites located in the same HER2HR combination at the observation date $d$, respectively.

Figure 2 illustrates the complementary nature of the ONDE network to the already existing HYDRO (http://www. hydro.eaufrance.fr, last access: 22 May 2018) French river flow monitoring network. The ONDE sites and a set of 1600 gauging stations available in the HYDRO database have been projected on the RHT (Theoretical Hydrographic Network; Pella et al., 2012) river network and the drainage area and the elevation have been estimated. A large part of ONDE sites are located on small headwater streams, with $70 \%$ of the sites with a drainage area of less than $50 \mathrm{~km}^{2}$, while most of the gauging stations record flows of catchments of medium size (between 100 and $500 \mathrm{~km}^{2}$ ). Only four stations display a drainage area of more than $1000 \mathrm{~km}^{2}$. The distributions of elevation of the two databases look similar. The ONDE sites are mostly located on rivers with an elevation below $200 \mathrm{~m}$ (75\% of sites). The ONDE sites are sparse at high elevations (95 sites located above $1000 \mathrm{~m}$ ). This bias is likely due to access difficulties in mountainous areas.

\subsection{POC dataset: a denser regional dataset used for independent validation}

A spatially denser citizen science dataset of flowstate observations in western France (Poitou-Charente region) (http://atlas.observatoire-environnement.org, last access: 22 May 2018) has been used as a validation dataset to test the robustness of our models calibrated with the ONDE dataset. The POC monitoring (2011-2013) covered more than $4000 \mathrm{~km}$ of river length across 20 catchments. Each river was entirely surveyed every 1 st and 15 th of each month be- 

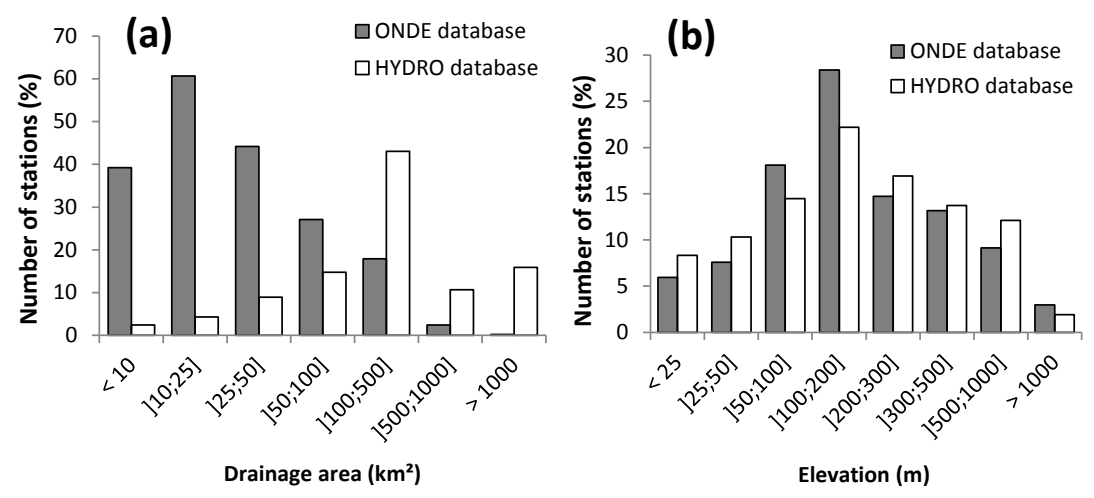

Figure 2. Distribution of the 3300 ONDE sites and of the 1600 gauging stations available in the HYDRO database against (a) drainage area and (b) elevation.

tween June and October, resulting in eight observations per year. Four intermittency statuses were available in the POC dataset (Datry et al., 2016a), but to allow comparisons with the ONDE network, we pooled the two "Flowing" and "Low Flow" POC statuses into a single "Flowing" status and the two "No flow" and "Dry" statuses into the "Drying" status. This dataset is available as maps with flow states assigned to the inspected streams. Values of RPoD at each POC observation date are calculated in the same way as RPoD $\mathrm{ONDE}$. Thus $\mathrm{RPoD}_{\mathrm{POC}}$ is given by the ratio between the number of drying statuses and the total number of observations at each inspected stream located in the same HER2-HR.

\subsection{Explanatory discharge dataset}

Two discharge datasets (continuous daily time series) were used as explanatory variables of discrete intermittence observations, with the objective of extrapolating the intermittence frequency over time. The two datasets included time series of daily discharge extracted from the French river flow monitoring network (HYDRO database, http://www.hydro. eaufrance.fr/, last access: 22 May 2018): (i) the 2011-2017 dataset with full records available between 1 January 2011 and 31 June 2017; (ii) the 1989-2017 dataset concerning a reduced number of gauging stations and providing daily discharges between 1 January 1989 and 31 June 2017. According to the hydrometric services in charge of the selected gauging stations, high quality of measurements was ensured and observed discharges were not or only slightly altered by human actions.

The 2011-2017 dataset was composed of 1600 gauging stations distributed across France. Each stream where a HYDRO gauging station is located has been defined as IRES or perennial. Several definitions of IRES can be found in the literature (Huxter and van Meerveld, 2012; Eng et al., 2016; Reynolds et al., 2015). In this study, we considered stations to be intermittent when five consecutive days with discharge less than $1 \mathrm{Ls}^{-1}$ have been observed during the period of record.

The 1989-2017 dataset consisted of 630 gauging stations selected with less than $5 \%$ of missing data (continuous or not) during the period 1989-2017. This dataset was thereafter used to estimate the regional probability of drying before the creation of the ONDE network.

\subsection{Explanatory groundwater-level dataset}

Because groundwater resources influence stream intermittence, we used available time series of the daily groundwater level available in the ADES database (http://www.ades. eaufrance.fr, last access: 22 May 2018) at sites identified as involved in groundwater-surface water exchanges (Brugeron et al., 2012). Similarly to the discharge data, two sets of groundwater-level data with records available over the two periods 2011-2017 and 1989-2017 have been selected. The level of alteration of groundwater levels by water withdrawal is unknown because no information is available at this scale.

The 2011-2017 dataset was composed of 750 piezometers with daily groundwater-level data with less than $5 \%$ of missing data (continuous or not). The selection of the 19892017 dataset was not easy because few groundwater-level measurements were available in the database before 2000 . For example, only five piezometers met the tolerance limit on missing values considered for the 1989-2017 discharge dataset. In order to extend the dataset and because groundwater levels were less variable than stream discharges, the proportion of permitted gaps was fixed to $20 \%$ between 1989 and 2017. This led us to select 150 piezometers. Thereafter, when the missing data period was less than 10 days, groundwater levels were reconstructed by linear interpolation in order to reduce the proportion of missing values to less than $5 \%$ for the 150 piezometers selected. 


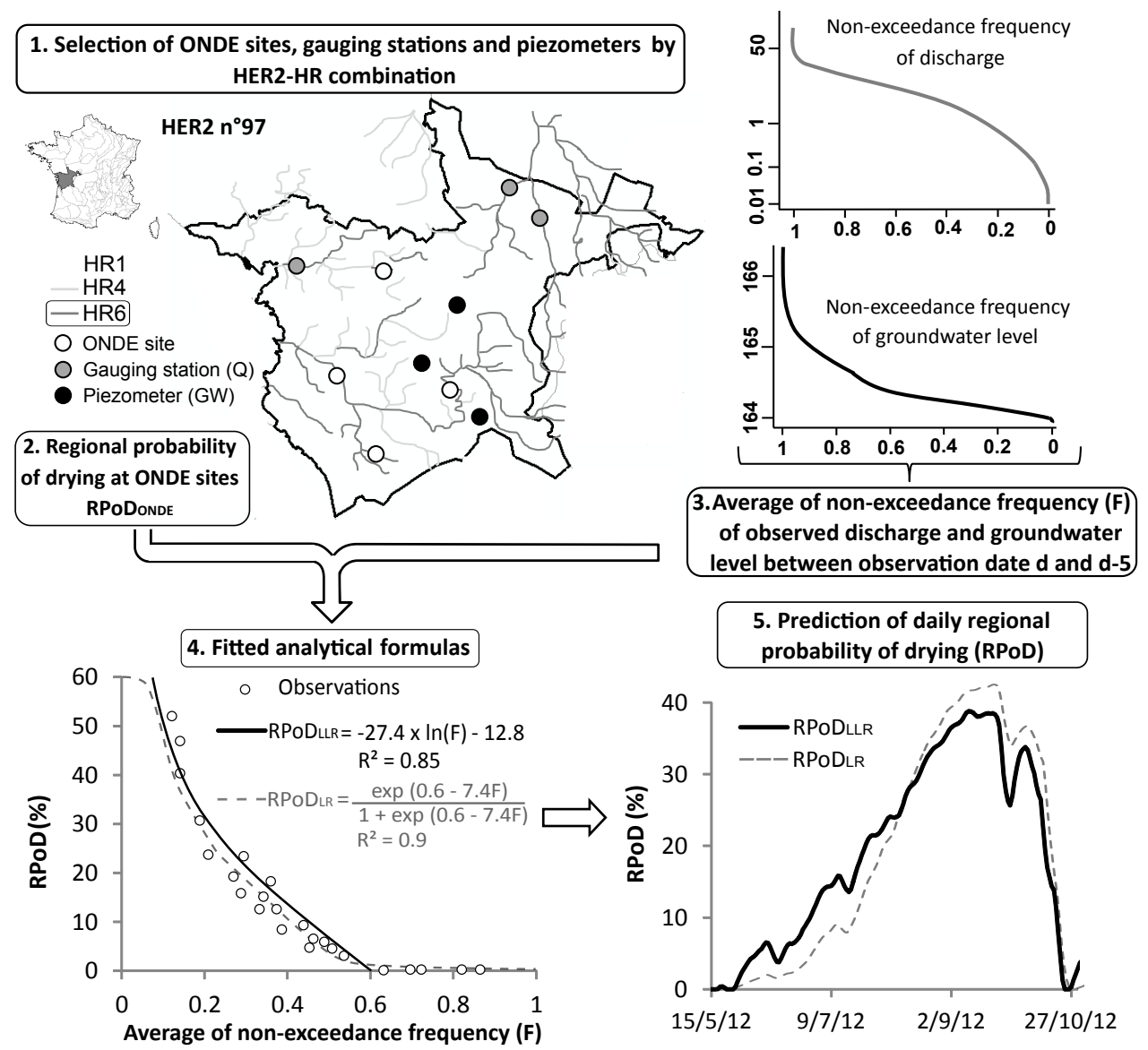

Figure 3. Strategy of parametric modelling (steps 1-4) developed to predict (step 5) the regional probability of drying (RPoD) by HER2-HR combination in France.

\subsection{Statistical modelling of regional probability of drying}

The parametric modelling strategy was based on five main steps (Fig. 3). The first step consisted in selecting all ONDE sites, gauging stations and piezometers located in the same HER2-HR combination. When the total number of gauging stations and piezometers was less than five for a HER2-HR combination, we merged the HER2-HR combination with a neighbouring one located in the same HER1. This was done for 20 of the 280 regions. The second step consisted in calculating the $\mathrm{RPoD}$ ONDE for each observation date $\left(5\right.$ year $\left.^{-1}\right)$ and for all selected ONDE sites. In a third step, a flow duration curve was determined for each selected HYDRO gauging station. The average non-exceedance frequency of the observed discharge at gauging stations was averaged for the date of observation $(d)$ at ONDE sites and the 5 days preceding the observation. The lag of 6 days accounted for the fact that ONDE survey dates in a region could differ by 5 days, and accounted for the inertia of physical processes (e.g. storage capacity). The same operation was carried out with selected piezometers. Finally the hydrological conditions are described by the average (across stations) $F$ of the non-exceedance frequencies of discharge $\left(F_{q}\right)$ and groundwater levels $\left(F_{\mathrm{gw}}\right)$ with respect to the relative proportions of gauging stations and piezometers:

$F(d)=\frac{\sum_{i=1}^{i=N_{q}} F_{q_{i}}+\sum_{j=1}^{j=N_{\mathrm{gw}}} F_{\mathrm{gw}_{j}}}{\left(N_{q}+N_{\mathrm{gw}}\right)}$,

where $F_{q_{i}}$ denotes the average non-exceedance frequency of discharge at the gauging station $i$ calculated between $d$ and $d-5 ; F_{\mathbf{g w}_{j}}$ the average non-exceedance frequency of groundwater levels at the piezometer $j$ calculated between $d$ and $d-5 ; N_{q}$ the number of gauging stations selected in a HER2HR combination; and Ngw the number of selected piezometers selected in the HER2-HR combination. The fourth step consisted in estimating the $\mathrm{RPoD}_{\mathrm{ONDE}}$ as a function of $F$. Two types of regression were fitted for each HER2-HR combination across France: 
- A truncated logarithmic linear regression (LLR), with two parameters $\alpha_{1}$ and $\beta_{1}$ :

$$
\begin{aligned}
& \operatorname{RPoD}_{\operatorname{LLR}}(d)= \\
& \qquad\left\{\begin{array}{l}
\min \left(1 ; \alpha_{1} \times \ln (F(d))+\beta_{1}\right) \text { when } F<F 0 \\
0 \text { when } F \geq F 0 .
\end{array}\right.
\end{aligned}
$$

F0 was fixed as the value of non-exceedance frequencies of discharge and groundwater levels at which no more drying status was observed across the ONDE network $\left(\mathrm{RPoD}_{\mathrm{ONDE}}=0\right)$.

- A logistic regression (LR) with two parameters $\alpha_{2}$ and $\beta_{2}$ :

$$
\begin{aligned}
\operatorname{Logit}\left(\operatorname{RPoD}_{\mathrm{LR}}(d)\right) & =\ln \left(\frac{\operatorname{RPoD}_{\mathrm{LR}}(d)}{1-\operatorname{RPoD}_{\mathrm{LR}}(d)}\right) \\
& =\alpha_{2} \times F(d)+\beta_{2} .
\end{aligned}
$$

LR is a multivariate analysis method well known for its relevance in binary classification issues (Lee, 2005). The $\mathrm{RPoD}_{\mathrm{LR}}$ was then calculated as follows in Eq. (5):

$$
\operatorname{RPoD}_{\mathrm{LR}}(d)=\frac{\exp \left(\alpha_{2} F(d)+\beta_{2}\right)}{1+\exp \left(\alpha_{2} F(d)+\beta_{2}\right)} .
$$

Models were calibrated against observations available during the same period, 2012-2016, leaving out the year 2017 for an independent validation test. However, for the continuous temporal extrapolations (one over 2011-2017, the other over 1989-2017), two models were built with different piezometers and gauging stations selected as explanatory variables (see Sects. 2.4 and 2.5). Thus there are two sets of regression parameters specific to each dataset for both the LLR and LR models, leading to different prediction of RPoD.

Finally, in a fifth step, a daily regional probability of drying (RPoD) could be predicted for each HER2-HR combination with both models following analytical formulas (Eqs. 3 and 5).

\subsection{Model robustness: validation using independent datasets}

We used (1) the POC independent data and (2) the 2017 ONDE year to test the robustness of the LLR and LR model to predict the intermittence frequency (1) in space and (2) over time. Note that when predicting on the POC datasets, a new model was calibrated using only ONDE sites located out of POC streams.

For both datasets (POC and ONDE, 2017), the relative performance of the LLR and LR models was compared in multiple ways using both the 2011-2017 and 1989-2017 datasets. The performance of each model was evaluated by the Nash-Sutcliffe efficiency criterion (NSE) (Nash and Sutcliffe, 1970):

$\mathrm{NSE}=1-\frac{\sum_{i=1}^{N}\left(\mathrm{RPoD}_{\mathrm{ONDEi}}-\mathrm{RPoD}_{\mathrm{pri}}\right)^{2}}{\sum_{i=1}^{N}\left(\mathrm{RPoD}_{\mathrm{ONDEi}}-\overline{\mathrm{RPoD}_{\mathrm{ONDEi}}}\right)^{2}}$,

where $\mathrm{RPoD} \mathrm{DNDEi}_{\mathrm{O}}$ is the average proportion of drying statuses over the ONDE sites located in the HER2-HR combination at the $i$ th observation date, $\mathrm{RPoD}_{\text {pri }}$ is the predicted regional probability of drying at the $i$ th observation date, $\overline{\mathrm{RPoD}}_{\mathrm{ONDEi}}$ is the mean of $\mathrm{RPoD} \mathrm{DNDEi}_{\mathrm{O}}$ over the period and $N$ is the total number of observations in the ONDE network for each HER2-HR combination.

\subsection{Model prediction}

Both models have been calibrated over the period 2012-2016 and were then applied in a fifth step to predict the daily RPoD in France (Fig. 3). The RPoD was firstly predicted over the period 2012-2016 in order to identify the most affected regions by flow intermittence using the 2011-2017 datasets. The second application concerned the extrapolation of RPoD in France over a longer period using the 1989-2017 dataset to analyse the temporal variability of flow intermittence at the national level. It should be noted that model predictions only concern streams with a Strahler order of lower than 5 due to the ONDE site location.

\section{Results}

\subsection{Quantitative analysis}

\subsubsection{Inter-annual intermittence according to the raw discrete ONDE network}

A total of 1127 ONDE sites have recorded at least one drying event during the period 2012-2016 representing 35\% of the 3300 ONDE sites. From the ONDE database the probability of drying at the country scale was computed as the total number of drying statuses over France divided by the total number of ONDE observations available during statuses the same year (Fig. 4a). Between 2012 and 2016, the most critical year is 2012 , with $15 \%$ of drying statuses followed by $2016(14 \%)$ and 2015 (14\%) (Fig. 4a). The years 2013 and 2014 are less affected with only $6 \%$ of drying statuses observed (Fig. 4a).

Drying events mainly occur between July and September, but the evolution of the month's proportion of drying can differ between years (Fig. 4b). In more detail, water levels in 2012 decrease in August when the proportion of drying is $27 \%$, and the situation lasts until the end of September with $25 \%$ of drying (Fig. 4b). In 2013, the proportion of drying is 

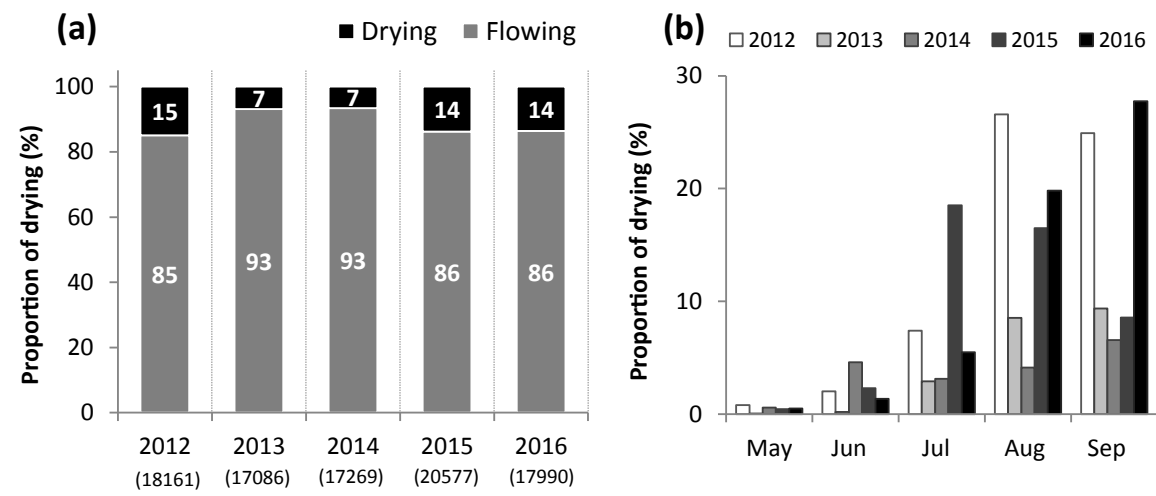

Figure 4. (a) Distribution of the yearly proportion of drying observed with the ONDE network with the total yearly number of ONDE observations written in brackets and (b) distribution of proportions of drying per year and per month.

lower than in 2012, but follows the same pattern with an increase at the end of July (3\%), reaching $9 \%$ in August and in September. In 2014, the first peak of drying (5\%) is reached early in June. Then, the proportion of drying decreases in July (3\%) and increases slightly in August (4\%), reaching $7 \%$ in September. In 2015, the critical period occurs at the end of July with $19 \%$ of drying statuses, and the proportion of drying decreases slightly at the end of August (17\%) until it reaches $9 \%$ in September. Finally, in 2016, the situation gradually deteriorates every month, reaching $20 \%$ of drying statuses in August, and $28 \%$ in September.

Between 2012 and 2016, a proportion of drying higher than $50 \%$ is recorded on 93 ONDE sites and their spatial distribution is very patchy at the scale of France (black and dark grey dots, Fig. 5a). There are only 158 ONDE sites with at least one drying event every year and a variability of drying locations can be observed across years. The southeast of France is heavily affected by rivers drying, where the proportion of drying can exceed $75 \%$ annually (black dots, Fig. 5b-f). The north-western part of France is less affected, although many ONDE sites show a proportion of drying observed above $50 \%$ in 2014 and 2016 (Fig. 5d and f). Northeastern France is rather affected in 2012, 2014 and 2015, where several ONDE sites have more than $75 \%$ of drying statuses (Fig. 5b, d and e). South-western France is particularly affected in 2012 and 2015 (Fig. 5b and e).

\subsubsection{Comparison of flow intermittence between the raw ONDE and HYDRO datasets}

The HYDRO dataset includes 90 gauging stations located on streams considered IRES, which represents only $5.6 \%$ of the 1600 gauging stations against $35 \%$ for ONDE sites. At the national scale, the number of IRES seems underrepresented in the south-western, central, and north-eastern parts of France and Corsica in comparison with sites experiencing drying in the ONDE network (Fig. 6).
Table 1. Annual statistics on flow intermittence calculated on HYDRO gauging stations between 1 May and 30 September.

\begin{tabular}{rrrr}
\hline $\begin{array}{r}\text { Stations with } \\
\text { at least one } \\
\text { drying event }\end{array}$ & $\begin{array}{r}\text { Stations with } \\
\text { drying }>50 \%\end{array}$ & $\begin{array}{r}\text { Frequency of } \\
\text { discharge }<1 \text { L s }^{-1}\end{array}$ \\
\hline 2012 & 79 & 19 & 32.7 \\
2013 & 47 & 14 & 37.9 \\
2014 & 54 & 15 & 32.9 \\
2015 & 76 & 21 & 31.1 \\
2016 & 71 & 19 & 28.6 \\
\hline
\end{tabular}

The number of gauging stations with at least one drying event (discharge $<1 \mathrm{~L} \mathrm{~s}^{-1}$ ) observed between May and September varies between 79 in 2012 and 47 in 2014 (Table 1). The lowest numbers of gauging stations with drying events are observed in the years 2013 and 2014, while the highest numbers are related to the years 2012, 2015 and 2016. This finding is consistent with the analysis of the ONDE network (Fig. 5a, d). The frequency of drying, corresponding to the ratio between the number of dry days and the total number of days between 1 May and 30 September (153 days), in contrast, is quite constant over the years ( $\sim 30 \%)$. The number of gauging stations with drying events over more than $50 \%$ of the time varies little between wet years (14 in 2013) and dry years (21 in 2015), unlike ONDE observations, suggesting a significant temporal variability in the frequency of drying between dry and wet years (Fig. 5).

\subsection{Validation of the predicted regional probability of drying}

\subsubsection{Regression results}

The LLR and LR models, calibrated over the period 20122016, perform well with the 2011-2017 dataset, with a mean NSE of 0.8 with the LR model against 0.7 with the LLR 

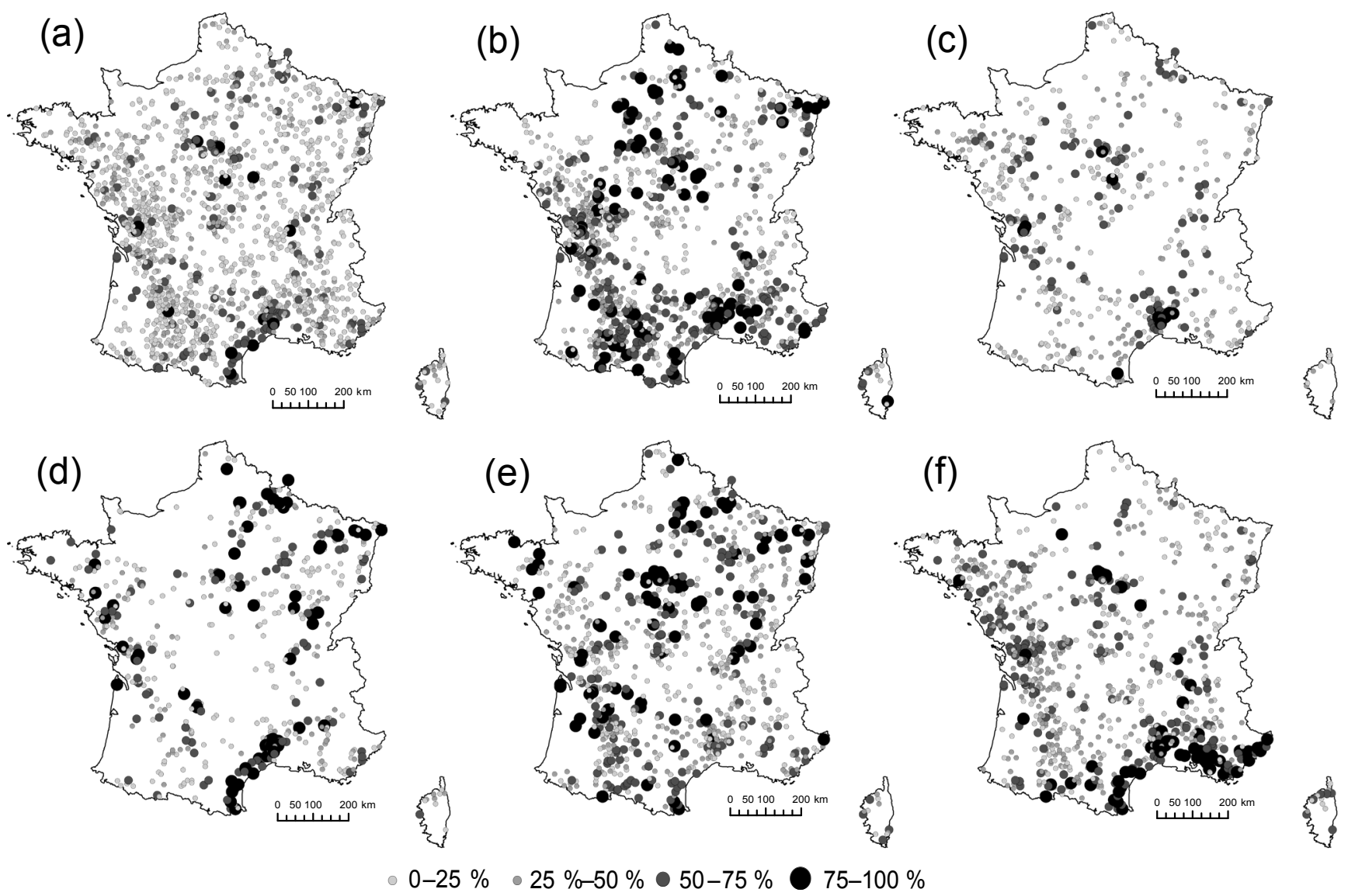

Figure 5. Distribution of the percentages of drying observed at ONDE sites for the years (a) 2012-2016, (b) 2012, (c) 2013, (d) 2014, (e) 2015 and (f) 2016 .

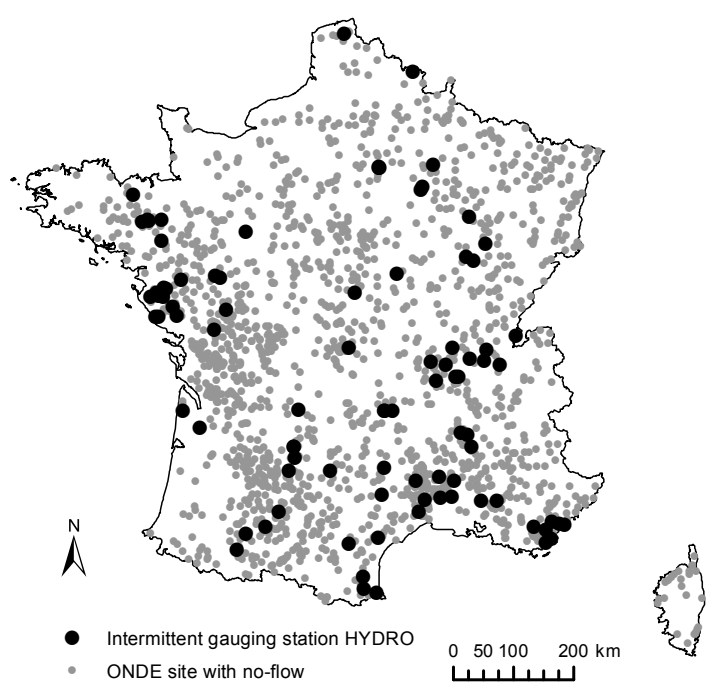

Figure 6. Map of ONDE sites and HYDRO gauging stations with at least one drying. model (Fig. 7a and b). With the LR model, $50 \%$ of the HER2-HR combinations obtain a NSE greater than 0.8 , representing a coverage of $65 \%$ of the French territory, while $33 \%$ of HER2-HR combinations display a NSE higher than 0.8 (50\% of coverage of France) with the LLR model. Regions with the highest performances are located in sedimentary plains, in the south-east of France and in the Pyrenees Mountains. Conversely, the worst performances are obtained in the mountainous regions of the Alps as well as in the Massif Central. In these regions the size of the HER2 is rather small and the number of ONDE sites, gauging stations and piezometers per HER2-HR combination are certainly too few to derive reliable relations. Despite pooling, estimating RPoD remains impossible for nine HER2-HR combinations ( $4.5 \%$ of coverage of France) because the number of ONDE sites, gauging stations and piezometer sites is insufficient (less than five) to perform the regression analysis.

The performance level is lower when the 1989-2017 dataset is used in models: the mean NSE with the LR and LLR models is 0.7 and 0.6, respectively (Fig. 7c and d). 

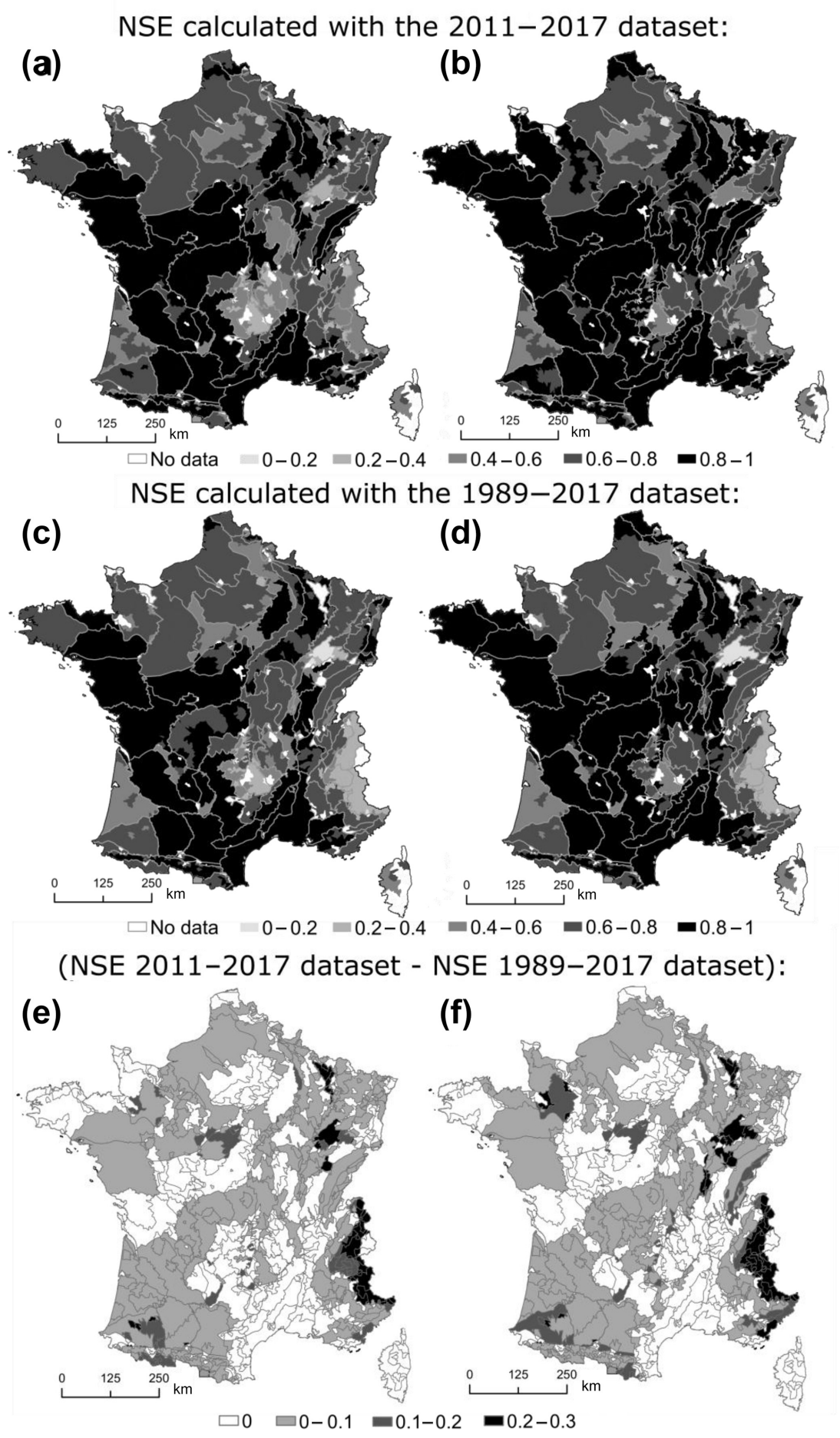

Figure 7. Map of Nash-Sutcliffe criteria (NSE) obtained for each HER2-HR combination between 2012 and 2016 with the 2011-2017 and 1989-2017 datasets according to (a) and (c) a log-linear regression (LLR) model; or (b) and (d) a logistic regression (LR) model. NSE differences between the 2011-2017 dataset and the 1989-2017 dataset are represented for (e) the LLR model and (f) the LR model.

The LR and LLR models lead to a similar performance range. However, the LR model outperforms the LLR model in terms of number of HER2-HR combinations, with NSE greater than 0.8 (Fig. $7 \mathrm{c}$ and d). The performance is sensitive to the dataset. As expected, the best results are obtained with the denser network. A decrease in NSE by more than 0.2 is identified for $5 \%$ of the French territory when the 19892017 dataset is used (black areas; Fig. 7e and f). The regions 
with the most degraded values of NSE are small HER2-HR combinations located in eastern France (Fig. 7e and f).

The decrease in performance is mainly due to the difference in the number of gauging stations and piezometers between the two datasets (Fig. 8). The most degraded NSEs correspond to HER2-HR combinations where the number of gauging stations and piezometers considered in regressions is the most reduced, i.e. with a loss higher than $50 \%$ of the stations (black and dark grey dots; Fig. 8a and b). However, the decrease in performance remains low (the difference in NSE is below 0.1 for 75 and $64 \%$ of HER2-HR combinations with the LLR and LR models, respectively).

\subsubsection{Comparison to the POC database}

The observed proportion of drying $\mathrm{RPoD}_{\mathrm{POC}}$ is rather well simulated by both LLR and LR models with the 2011-2017 explanatory dataset (NSE $>0.7$ except for the year 2011; Fig. 9). In addition, the models are able to capture small fluctuations of $\mathrm{RPoD}_{\mathrm{POC}}$ during the summer period. The best results during the year 2011 are obtained with the LLR model (black curve; Fig. 9) and the LR model overestimates RPoDPOC by $3 \%$ (dashed grey curve; Fig. 9). In 2012, the decline in water levels is more gradual than in 2011 and a marked peak is reached in September with $40 \%$ of RPoDPOC (Fig. 9). This pattern is well reproduced by both models with a good fit to all observation points (Fig. 9). The year 2013 is less affected by drying occurrence and the maximum RPoDPOC does not exceed $20 \%$ (Fig. 9). Curves of both models fit to observations well until the end of August. Note that the LR model is slightly closer to the observations around the peak in September compared to the LLR model. However, the LR model overestimates the RPoDPOC at the end of September and in October.

When the 1989-2017 dataset is used for explanatory variables, the simulations of RPoD are weakly degraded with both models (Fig. 9d, e, f). However, the simulated pattern is similar to the observed one. The LLR model outperforms the LR model during the 3 years of validation with the 19892017 dataset (black curve; Fig. 9d, e, f).

\subsubsection{Temporal patterns assessment of models between 2012 and 2017}

During the calibration period, the LLR and LR models tend to better simulate the RPoD during dry years 2012 and 2016 $(\mathrm{NSE}=0.8$ with the LLR and LR models; Table 2) than during wet years (e.g. 2014 with NSE<0.7). The NSEs are lower during the months of May and June when few drying events are observed, while NSEs are much better during the driest months of August and September.

During the validation year of 2017, both models obtain a similar performance over the year independent of datasets $(\mathrm{NSE}=0.7)$.
Monthly NSEs in 2017 follow the same trend as monthly NSEs of the calibration period, with lower NSEs in May $($ NSEs $<0.4)$ and June (NSEs $=0.5$ ) and higher NSEs in July, August and September (NSEs $=0.6$ ) with both models independent of datasets. Figure 10 shows the dispersion between predicted RPoD and drying statuses observed at ONDE sites in the scatter plot during the validation year 2017 (Fig. 10a and b) in comparison with the year 2012, which obtains the better NSE during calibration period (Fig. 10c and d). The NSEs obtained in 2017 are 0.72 with the LLR model and 0.68 with the LR model against 0.83 and 0.81 in 2012, respectively. The performance is slightly lower in 2017 but remains acceptable with NSEs close to 0.7, and both models seem able to predict RPoD from the calibration period.

\subsection{Application of regional models}

\subsubsection{Modelling of intermittencies severity between 2012 and 2016}

Both models have been applied using the 2011-2017 dataset. Figure 11 displays the maximum number of consecutive days $\left(\mathrm{D}_{\mathrm{RPoD}}>20 \%\right)$ with RPoD higher than $20 \%$ simulated by both the LLR and LR models. The most affected regions are located in the south-east of France and in the sedimentary plains, which is consistent with the spatial pattern obtained from the ONDE observations (Fig. 5). The most impacted year followed the same hierarchy: the year 2012 is the most critical year, with $30 \%$ of France displaying $\mathrm{D}_{\mathrm{RPoD}}>20 \%$ higher than 60 days followed by the year 2015 (20\% of France with $\mathrm{D}_{\mathrm{RPoD}}>20 \%>60$ days) and $2016(15 \%$ of France with $\mathrm{D}_{\mathrm{RPoD}}>20 \%>60$ days) (Fig. 11). The years 2013 and 2014 are weakly affected, with $5 \%$ and $6 \%$ of France with $D_{R P o D}>20 \%$ higher than 60 days, respectively.

The LR model tends to simulate shorter periods of drying, particularly in HER2-HR combinations located in southeastern France in 2013 and 2014 (Fig. 11). However, there is an overall agreement between RPoD simulated by both models in terms of spatial and temporal extent of dry streams.

\subsubsection{Reconstitution of historical regional probability of drying}

The trend temporal patterns of RPoD predicted by the two models, considering the 1989-2017 dataset, look similar between 1989 and 2016, and the simulated RPoD fit well to RPoD ONDE (Fig. 12).

The proportion of drying is highly variable over the total simulation period, with alternating dry (1989 to 1991, 2003 to 2006, 2009 to 2012) and wet (1994 to 1995, 2000 to 2002,2013 to 2014) phases. In spite of inter-annual variability, peaks of RPoD occur regularly between August and September, whether in dry years or wet years. This finding is consistent with the preeminence of rainfall-fed river flow regimes with low flows in summer, in France. 

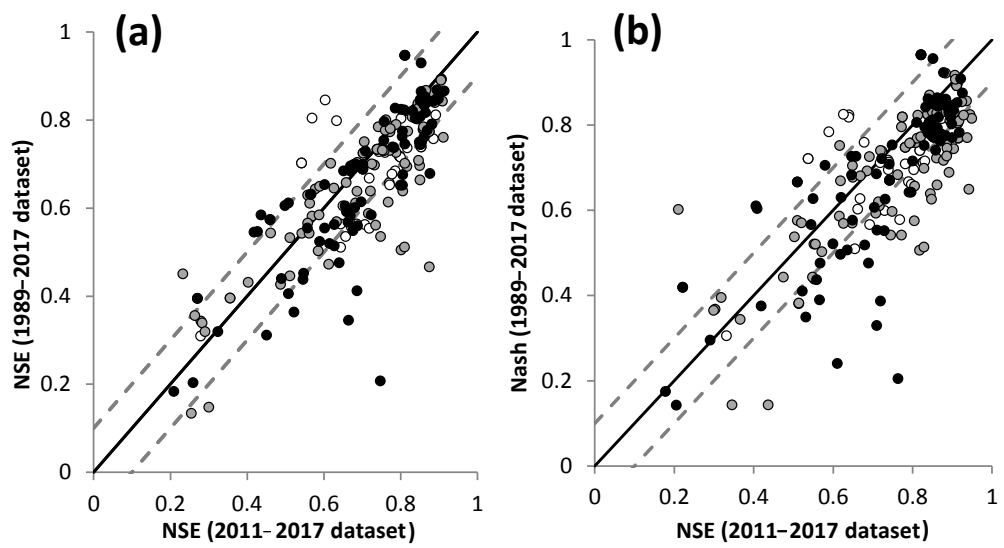

Figure 8. NSE calculated for each HER2-HR combination between 2012 and 2016 with the 1989-2017 dataset as a function of NSE calculated with the 2011-2017 dataset with, respectively, (a) the LLR model and (b) the LR model. The colours of the dots represent the proportion of gauging stations and piezometers lost between the 2011-2017 database and the 1989-2017 database: losses < 50\% (white); losses between 50 and $75 \%$ (grey); losses $>75 \%$ (black).

The highest values of RPoDs (above $35 \%$ over France) are observed in 1989, 1990, 1991, 2003 and 2005 (black curve, Fig. 12a and b). The RPoDs simulated during these dry years are out of the range of the observed values over the calibration period (2012-2016). Estimations are thus uncertain. However, the high values of $\mathrm{RPoD}$ are consistent with observations reported in previous studies (e.g. Larue and Giret, 2004; Snelder et al., 2013; Caillouet et al., 2017). Conversely, the years less affected by drying are simulated in 1994, 2001 and 2014, with an average RPoD below $15 \%$ throughout the year (black curve, Fig. 12a and b).

Results obtained with the LLR model are more contrasted in terms of extreme values than those obtained with the LR model (Fig. 12b).

\section{Discussion}

\subsection{ONDE network complementarity with conventional flow monitoring network}

The analysis of the ONDE observations shows that the proportion of rivers undergoing drying is significantly higher $(35 \%)$ than that observed with the conventional monitoring (HYDRO database, $8 \%$ ). This proportion, although related to a short period of records 2012 and 2016, is consistent with the percentage of $39 \%$ of river segments classified as intermittent by Snelder et al. (2013). This analysis confirms the under-representation of IRES in the French HYDRO database, and probably others in other countries (flows are often uncontrolled in IRES). Without gauging stations located on headwaters, Snelder et al. (2013) were unable to predict IRES in eastern France (see Fig. 9, p. 2694). The high density of ONDE sites makes it possible to improve the detection of drying events and lead to better understand the spatial distribution of IRES located at the upstream extent of the hydrographic network. The ONDE network encompasses various hydrological conditions, which provides a more accurate assessment of inter-annual variability, differentiating between dry years (2012, 2015 and 2016) and wet years $(2013,2014)$ with clearly few drying occurrences.

The validation of the LR and LLR models against the spatially dense POC database also demonstrates the spatial representativeness of the ONDE network. Thanks to the qualitative information provided and to models such as the statistical models developed here, it is now possible to capture drying events at the regional scale.

The ONDE sites are located on small headwater streams which can be very reactive to external disturbances (rainfall deficit, change in air temperature, increase in water withdrawals, etc.) and by nature are more likely to be IRES. The gauging stations available in the HYDRO database are located on larger streams and their hydrologic response to changes in external factors (environmental or human) is slower and drying occurred with greater inertia under temperate climate. Their uneven distribution across France does not allow us to accurately characterise the inter-annual variability of drying development. Overall, the ONDE network provides very complementary information to conventional flow monitoring, leading to a better understanding of the processes of drying in upstream catchments.

\subsection{Dependency on spatial gauging network density}

The performance obtained with the LR and LLR models is slightly better with the 2011-2017 dataset (mean NSE $=0.75$ ) than those obtained with the 1989-2017 dataset (mean NSE > 0.65), whose network is less dense. HER2-HR combinations are the most degraded where the number of monitoring stations is the most decreased between the two 
RPoD simulated with the 2011-2017 dataset:
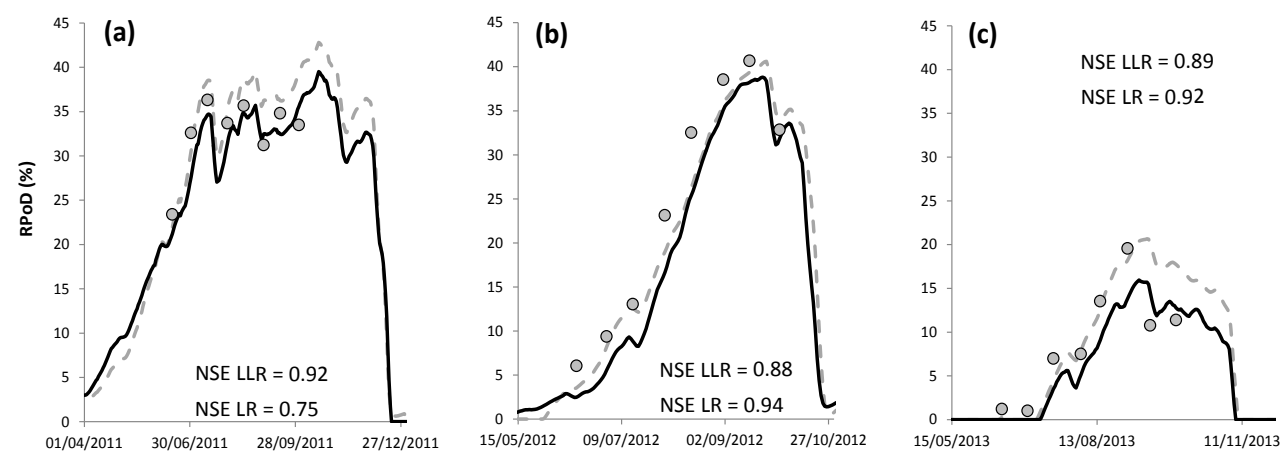

RPoD simulated with the 1989-2017 dataset:
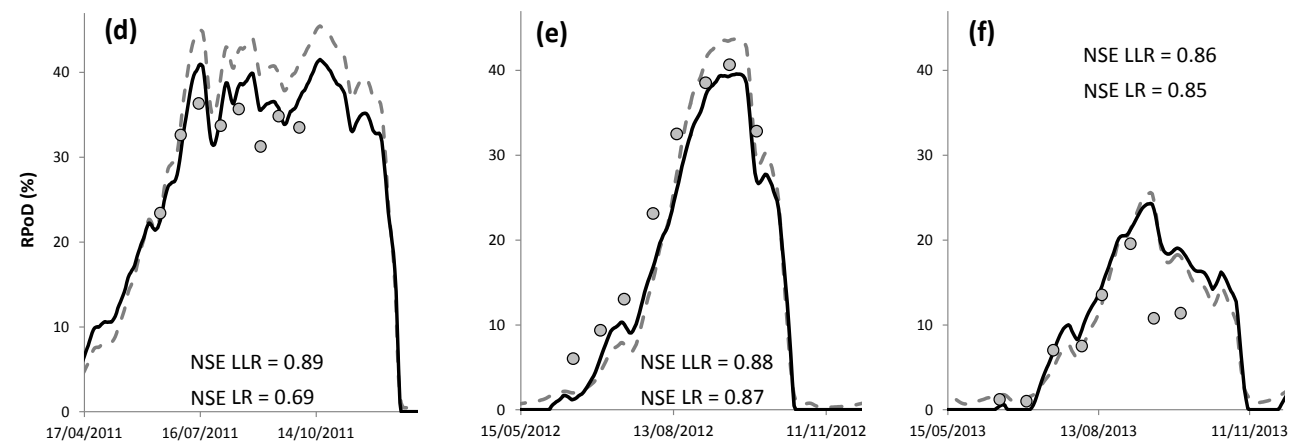

LLR model

- LR model O Obs - POC data

Figure 9. Comparison between observed proportion of drying RPoD $D_{P O C}$ and RPoD predicted by the LLR and LR models with the 2011-2017 dataset in (a) 2011, (b) 2012 and (c) 2013 and with the 1989-2017 dataset in (d) 2011, (e) 2012 and (f) 2013.

Table 2. NSE criteria obtained between 2012 and 2017 with the LLR and LR models calibrated over the period 2012-2016.

\begin{tabular}{|c|c|c|c|c|c|c|c|c|c|c|c|c|c|}
\hline & & \multicolumn{6}{|c|}{ 2011-2017 dataset } & \multicolumn{6}{|c|}{ 1989-2017 dataset } \\
\hline & & \multicolumn{5}{|c|}{ Calibration } & \multirow{2}{*}{$\begin{array}{c}\text { Valid. } \\
2017\end{array}$} & \multicolumn{5}{|c|}{ Calibration } & \multirow{2}{*}{$\frac{\text { Valid }}{2017}$} \\
\hline & & 2012 & 2013 & 2014 & 2015 & 2016 & & 2012 & 2013 & 2014 & 2015 & 2016 & \\
\hline \multirow{6}{*}{ LLR model } & May & 0.2 & 0.0 & 0.5 & 0.5 & 0.6 & 0.4 & 0.2 & 0.0 & 0.3 & 0.0 & 0.7 & 0.2 \\
\hline & Jun & 0.6 & 0.3 & 0.8 & 0.5 & 0.8 & 0.5 & 0.6 & 0.3 & 0.5 & 0.3 & 0.8 & 0.5 \\
\hline & Jul & 0.7 & 0.5 & 0.6 & 0.6 & 0.8 & 0.7 & 0.7 & 0.5 & 0.5 & 0.4 & 0.8 & 0.6 \\
\hline & Aug & 0.8 & 0.6 & 0.7 & 0.7 & 0.8 & 0.6 & 0.7 & 0.5 & 0.5 & 0.5 & 0.8 & 0.6 \\
\hline & Sep & 0.7 & 0.8 & 0.6 & 0.6 & 0.7 & 0.6 & 0.6 & 0.7 & 0.5 & 0.5 & 0.6 & 0.6 \\
\hline & May-Sep & 0.8 & 0.8 & 0.7 & 0.7 & 0.8 & 0.7 & 0.8 & 0.7 & 0.5 & 0.6 & 0.8 & 0.7 \\
\hline \multirow{6}{*}{ LR model } & May & 0.2 & 0.0 & 0.5 & 0.1 & 0.6 & 0.3 & 0.3 & 0.0 & 0.3 & 0.0 & 0.7 & 0.2 \\
\hline & Jun & 0.6 & 0.5 & 0.8 & 0.5 & 0.8 & 0.4 & 0.6 & 0.4 & 0.5 & 0.3 & 0.7 & 0.4 \\
\hline & Jul & 0.7 & 0.6 & 0.5 & 0.6 & 0.8 & 0.6 & 0.7 & 0.4 & 0.5 & 0.4 & 0.8 & 0.6 \\
\hline & Aug & 0.7 & 0.6 & 0.7 & 0.6 & 0.7 & 0.6 & 0.6 & 0.4 & 0.5 & 0.4 & 0.7 & 0.5 \\
\hline & Sep & 0.6 & 0.8 & 0.6 & 0.7 & 0.7 & 0.6 & 0.5 & 0.6 & 0.4 & 0.5 & 0.6 & 0.6 \\
\hline & May-Sep & 0.8 & 0.8 & 0.7 & 0.7 & 0.8 & 0.7 & 0.8 & 0.7 & 0.5 & 0.6 & 0.8 & 0.7 \\
\hline
\end{tabular}



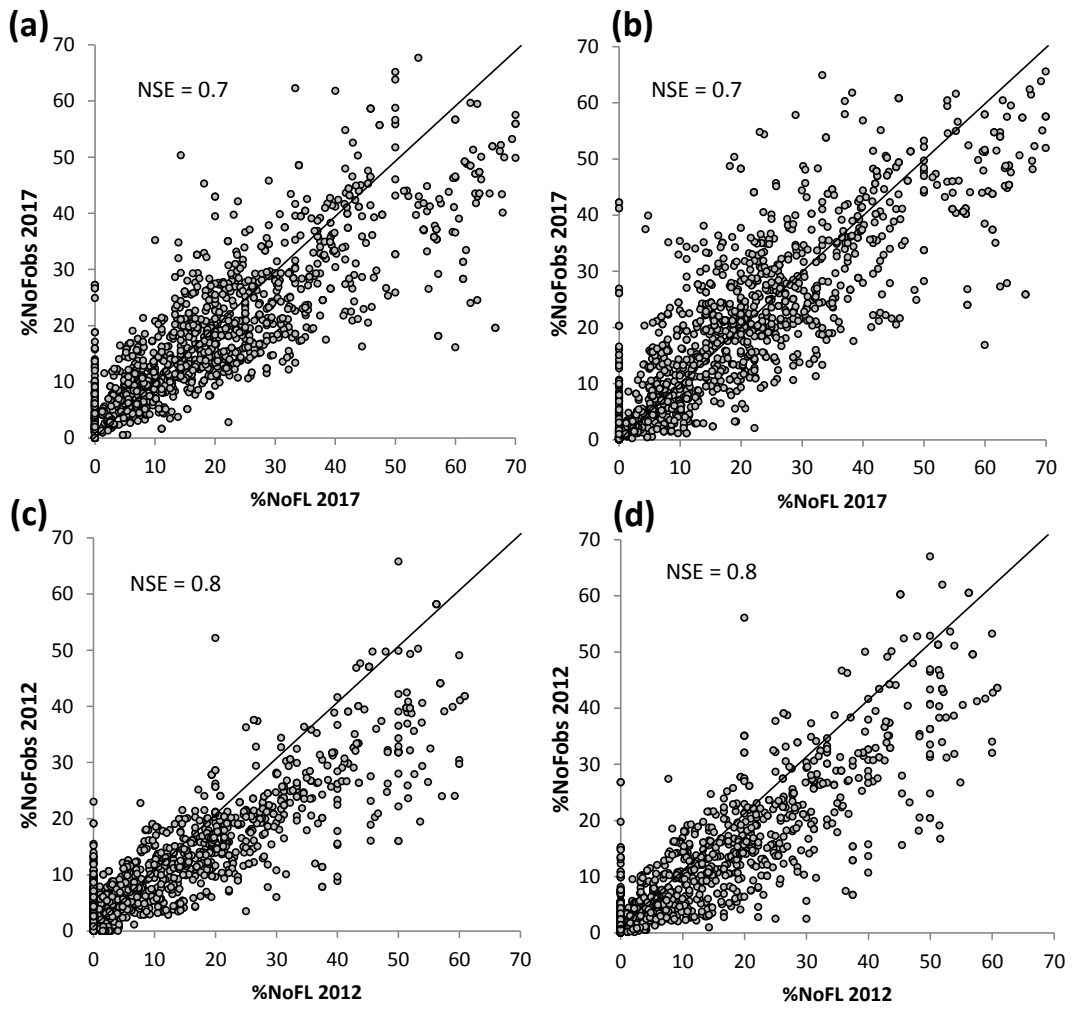

Figure 10. Scatter plot of the predicted RPoD ( $x$ axis) and drying observed at ONDE sites ( $y$ axis) in 2017 and 2012 simulated with the 2011-2017 dataset by (a and c) the LLR model and (b and d) the LR model.

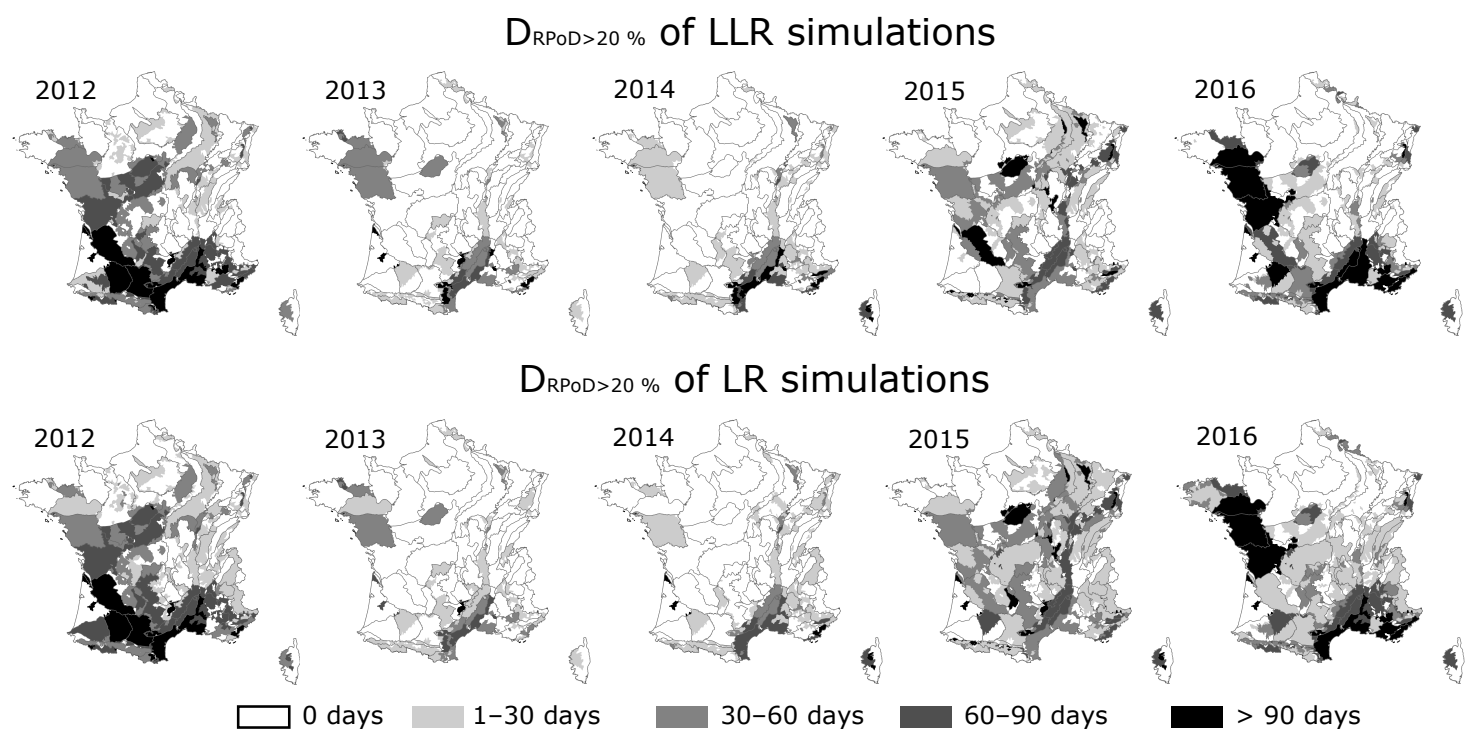

Figure 11. Maximum duration of consecutive days with RPoD higher than $20 \%$ simulated with the LLR and LR models.

datasets. The accuracy of the predictions is dependent on the number of gauging stations, ONDE sites and piezometers available to calibrate the regressions. The highest NSEs are obtained in western sedimentary plains and south-eastern
France, where a significant number of streams have dryings regardless of years (Fig. 5). The dominant river flow regime in these regions is mainly influenced by precipitation and the lowest water levels are reached in August and September, 

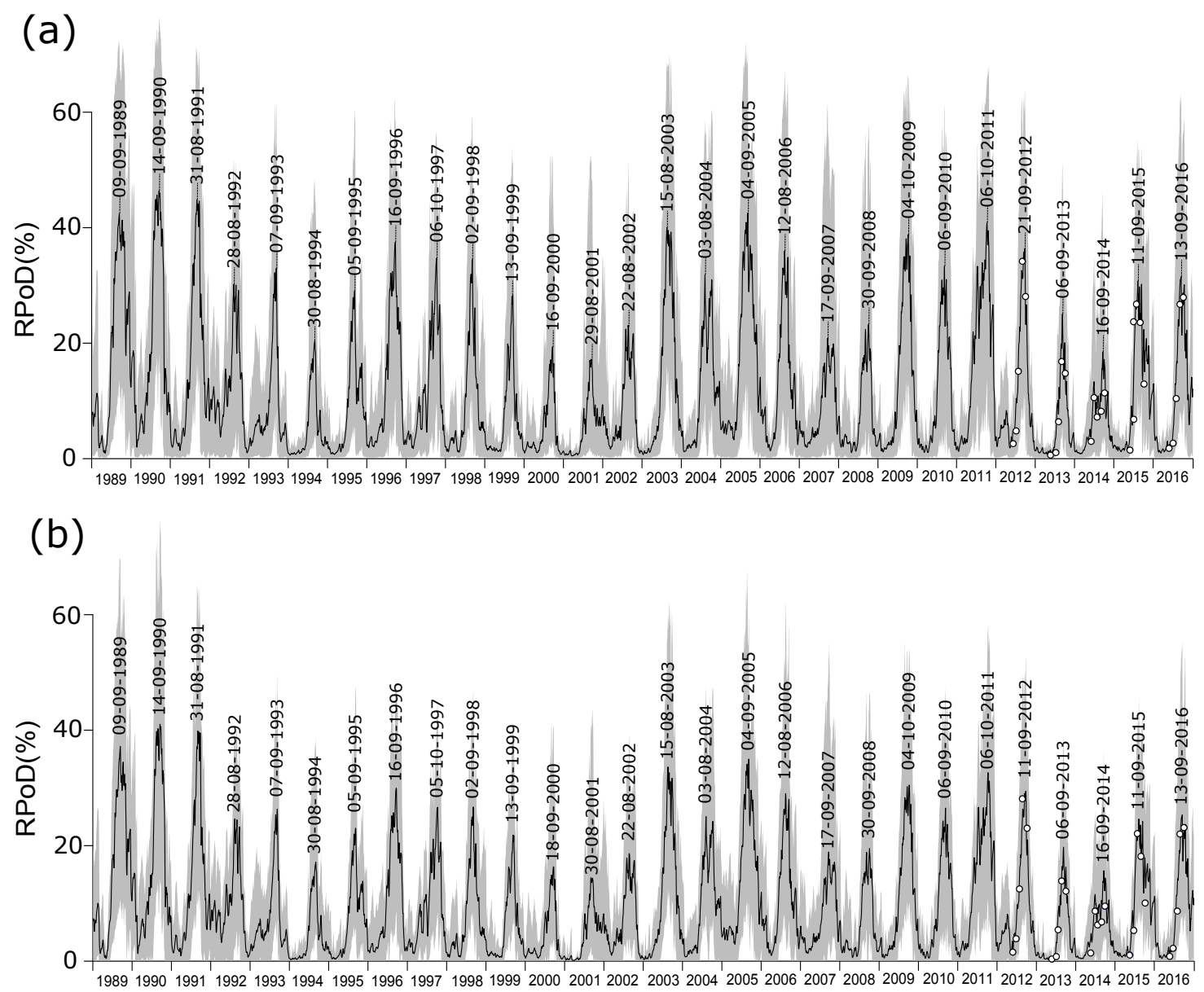

Figure 12. RPoD simulated between 1989 and 2016 with the 1989-2017 dataset with (a) the LR model and (b) the LLR model. The grey area represents the RPoD between the 90th percentile and the 10th percentile simulated on the HER2-HR combination, the black curve

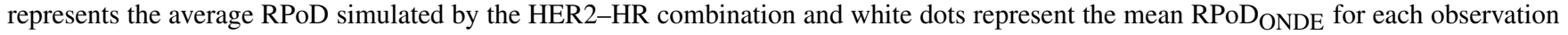
date. Dates mentioned correspond to the day of the maximum average RPoD simulated by the HER2-HR combination (black curve) of each year.

which corresponds to the monitoring period of the ONDE database. They benefit from a dense monitoring network (gauging stations, ONDE sites, piezometers), which allows a better representation of the hydrological functioning of streams located within the same HER2. Conversely, performance was poor in mountainous areas such as in the Alps or the Massif Central $(\mathrm{NSE}<0.4)$ where river flow regimes are diversified combining rainfall and snowmelt influences. By construction, the area of HER2-HR combination in mountains is reduced, which leads to a limited number of monitoring stations, certainly not sufficient to fit the models. Moreover, the observation period for ONDE sites was limited between May and September and dryings can be missed, particularly for streams influenced by snow or ice melting with potential drying periods in winter. In regions potentially concerned with drying events from the May-September period, the actual ONDE monitoring strategy needs to be adapted to provide reliable temporal observations and extrapolations of drying frequencies.

We have chosen to average the non-exceedance frequencies of flows and groundwater levels in order to increase the monitoring network. If models had been calibrated using only gauging stations, performance will have been globally similar, or slightly better, in some HER2-HR combinations (Fig. 13). Therefore, we could not validate the real gain of using groundwater-level data in addition to discharge data. This is certainly due to the dominant proportion of the gauging stations compared to the piezometers. Indeed, in the 2011-2017 dataset, the proportion of gauging stations is greater than $75 \%$ for more than $70 \%$ of HER2-HR combinations, whereas the proportion of piezometers exceeds $70 \%$ in only $5 \%$ of HER2-HR combinations. Groundwaterlevel data thus have a small weight in regressions for this dataset. However, in the 1989-2017 dataset, the proportion 

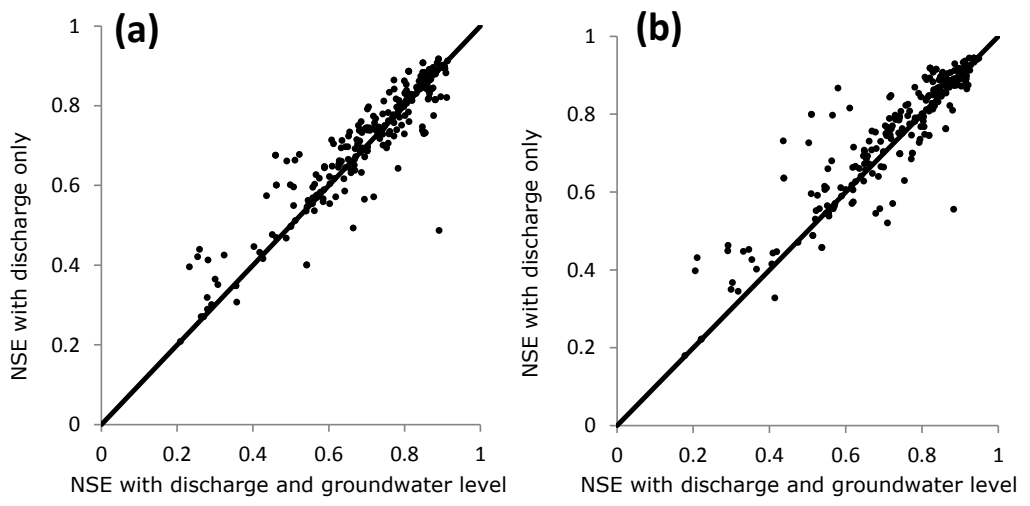

Figure 13. Comparison of NSE obtained with regression including only the discharge variable as a function of NSE obtained with discharge and groundwater-level variables in the 2011-2017 dataset with (a) the LLR model and (b) the LR model.

of piezometers is greater than $70 \%$ in more than $30 \%$ of HER2-HR combinations. The presence of piezometers increases the density of the monitoring network in HER2-HR combinations with few available gauging stations. Thanks to groundwater-level data, RPoD can be predicted on more HER2-HR combinations.

\subsection{Interest in reconstructing the dynamic regional probability of drying}

Spatio-temporal simulation of the probability of drying is crucial for advancing our understanding of IRES ecology and management. Some aquatic species can persist in a dry reach for a few days, weeks or months, while some are highly sensitive to desiccation (Datry, 2012; Storey and Quinn, 2013; Stubbington and Datry, 2013). Estimation of the total duration of days with drying at the reach scale is therefore needed to understand biological patterns in river networks (Kelso and Entrekin, 2018). To our knowledge, no study has proposed to reconstruct daily flow-state time series of headwater streams at the country scale such as France $\left(>500000 \mathrm{~km}^{2}\right)$ using discrete observations in time and space. In the literature, studies at national scale remain focused on the detection and the mapping of IRES because these rivers are historically poorly investigated and their proportion in existing hydrographic networks remains inaccurate or misunderstood (Nadeau and Rains, 2007; Snelder et al., 2013). Recently, several studies proposed alternative methodologies in order to estimate metrics in ungauged IRES (Gallart et al., 2016) or to predict daily streamflow in river basins experiencing flow intermittence (De Girolamo et al., 2017b), but remain applicable at the local scale.

This study provides a first regional approach to use discrete data obtained from regular observations. The average non-exceedance frequency is a global hydrological statistic that only captures the hydrological conditions at the regional scale in modelling the RPoD. For rainfall-driven river flow regimes, the effect of rainfall events on flow intermittence at the HER2-HR scale is probably indirectly reflected by the daily discharge and groundwater levels used to calculate the average non-exceedance frequency. However, when more observation data are available, it is likely that including more detailed descriptors of rainfall events and local geology could improve our approach. In France, based on the 2011-2017 dataset, both models suggest the highest values of RPoD along the Mediterranean coast $\left(\mathrm{D}_{\mathrm{RPoD}}>20 \%>100\right.$ days each year). Rivers in this region are subject to a predominantly pluvial regime (Class 7; Sauquet et al., 2008), i.e. hot and dry summers followed by intense rainfall events in autumn, leading to high flows in November (Skoulikidis et al., 2017b). The catchments in this region are small and particularly reactive to environmental changes, making them highly sensitive to flow intermittence. Rivers located in the sedimentary plain in western France are also very impacted by flow intermittence. The regime is also influenced by precipitation and for the basins subject to intense agriculture significant water abstractions during summer in this region reduce water availability in rivers and in aquifers which are no longer able to support the low water levels, leading to increased flow intermittence. Regarding alteration issues in our datasets, we do not have access to the exact location and the volumes of water withdrawal for irrigation purposes. However, due to their upstream location, water availability is expected to be low, which may limit potential withdrawals and as a consequence flow alteration at ONDE sites. The alteration of groundwater levels is unknown because no information is available. However, in sedimentary plains where agricultural crops dominate the landscape, we are not sure that no human action affects low flows. It is important to note that the responses of biological communities to artificial flow intermittence are still poorly understood compared to natural IRES (Datry et al., 2014b; Skoulikidis et al., 2017a). 

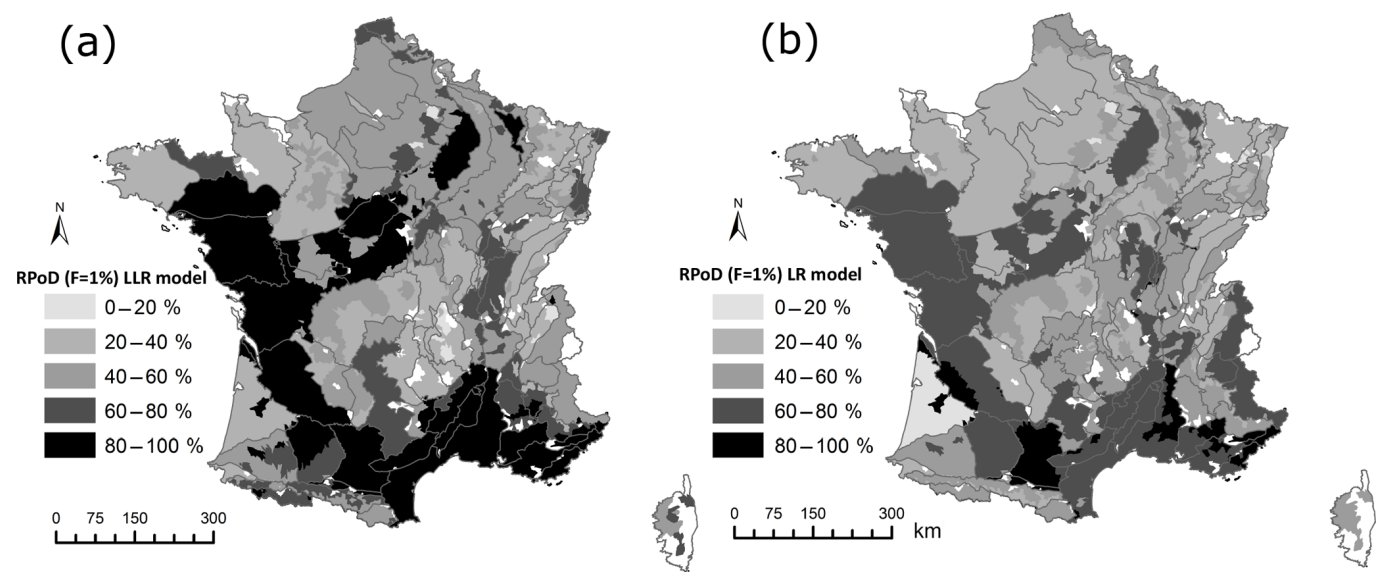

Figure 14. Regional probability of drying simulated with $F=1 \%$ predicted with (a) the LLR model and (b) the LR model.

\subsection{Validity of historical regional probability of drying during severe low-flow period}

The second application aimed at reconstructing historical RPoD over the period 1989-2016. Both models suggest the highest values of mean RPoD (>35\%) in 1989-1991, 2003 and 2005. During these dry years, predicted values of RPoD result from extrapolation but are consistent with published studies (Mérillon and Chaperon, 1990; Moreau, 2004). For example, Mérillon (1992) estimated that for the whole of France, $11000 \mathrm{~km}$ of rivers were dried at the end of the summers of 1989 and 1990. Caillouet et al. (2017) found that the low-flow event observed in 1989-1990 was particularly severe in terms of duration and affected $95 \%$ of France. Snelder et al. (2013) showed from 628 gauging stations that the years 1989-1991, 2003 and 2005 witnessed particularly high values of duration and frequency of drying events. They found that regions with the highest probability of drying were located along the Mediterranean and Atlantic coasts, which is consistent with ONDE observations and with our results.

Both models suggest the same sequence of dry and wet years. However, the application of the LLR model leads to less contrasted RPoD than the LR model (Fig. 12).

To illustrate these differences, the RPoD has been simulated by both models with an extreme $F$ of $1 \%$ (Fig. 14). The $\mathrm{RPoD}_{\mathrm{LLR}}$ is significantly higher and exceeds $80 \%$ in $30 \%$ of the study area against only $5 \%$ of the area with the $\mathrm{RPoD}_{\mathrm{LR}}$. On the other hand, models simulate low RPoD in HER2HR combinations where the RPoD $D_{\mathrm{ONDE}}$ is very low between 2012 and 2016, even when $F$ was $1 \%$, because this situation never occurred during the calibration period (Fig. 14). The logistic function of the LR model takes an S-shape which induced a decrease in the slope of the curve toward extreme values observed during the calibration period (2012-2016). The truncated logarithmic function of the LLR model is not bounded and RPoD can reach $100 \%$ during extreme lowflow events by extrapolation. Since the ONDE network mon- itoring period does not include a period with drought as severe as in the 1990s, it is not currently possible to assess the relative performance of the two models. Refining extrapolated values requires additional information on headwater collected during more severe droughts than those observed during the last 5 years and then gives support to the pursuit of the ONDE network.

\section{Conclusion}

This paper investigates the spatial and temporal dynamics of the regional probability of drying (RPoD) of headwater streams by taking benefit from qualitative and discontinuous data provided by the ONDE network. Two models based on linear or logistic regressions have been developed and succeeded in reconstructing the temporal dynamics of RPoD. They are based on a strong relationship between the nonexceedance frequencies of discharges and groundwater levels as a function of the proportion of drying statuses observed at ONDE sites per HER2-HR combination. LLR and LR models show similar performance and perform well between 2011 and 2017. The accuracy of predictions is dependent on the number of gauging stations, ONDE sites and piezometers available to calibrate the regressions. Regions with the highest performance are located in the sedimentary plains, where the monitoring network is dense and where the RPoD is the highest. Conversely, the worst performances are obtained in the mountainous regions. Finally, both models have been used to reconstruct historical RPoD between 1989 and 2016 and suggest the highest values of mean RPoD (>35\%) in 1989-1991, 2003 and 2005. This is consistent with other published studies, but the high density of ONDE sites makes it possible to improve the detection of drying events and lead to better capturing of the spatial distribution of IRES located at the upstream extent of the hydrographic network. Moreover, the duration of drying is of importance for ecologists 
and the prediction of a daily $\mathrm{RPoD}$ provides one key driver for the composition and persistence of aquatic species.

From a methodological point of view, our method relating discrete drying observation obtained by citizen science networks to continuous daily gauging data seems robust across the highly diverse (climate and topography) regions of France, and provides good predictions in an independent region excluded from the calibration process $(\mathrm{PoC})$. These two results suggest a potential application of our approach in other countries. Citizen science creates opportunities to overcome the lack of hydrological data, contributes to densifying the flow-state observation network (Turner and Richter, 2011; Buytaert et al., 2014) and remains less expensive than the installation of additional gauging stations to survey flow intermittence. The next step will be to use this regional approach to simulate the RPoD in future periods by taking into account effects of climate change through predicted discharge and groundwater-level data. This would allow quantification of the evolution of the probability of drying between the current period and the different climate projections provided by the latest IPCC Report (IPCC 2014) and would assist decision makers in defining protocols for restoring flows with appropriate measures to preserve aquatic ecosystems (Woelfle-Erskine, 2017).

Secondly, further work is needed to develop an approach capable of reconstructing the drying dynamics locally by differentiating each stream. Our approach remains spatially valid for estimating RPoDs at the scale of HER2-HR combinations, but does not allow characterisation of the variability of drying occurrence between nearby streams within these regions. From a methodological point of view, statistical tools such as neural networks (Breiman, 2001) have shown good ability to assess both the occurrence and extent of perennial and temporary segments (González-Ferreras and Barquín, 2017) and could be investigated as an alternative method to reconstruct locally the temporal variability of drying.

Data availability. Data used in this study are freely available on the Eaufrance data portal (http://www.eaufrance.fr; AFB, 2018). Time series of daily regional probability of drying are available upon request from the corresponding author.

Author contributions. AB, NL and ES developed the main ideas and designed the experiments. $\mathrm{AB}$ implemented the algorithms and analysed the results. $\mathrm{AB}$ prepared the manuscript with contributions from all co-authors.

Competing interests. The authors declare that they have no conflict of interest.

Acknowledgements. The authors wish to thank Anne van Loon and Catherine Sefton for their valuable comments, suggestions and positive feedback on the manuscript. The research project was partly funded by the French Agency for Biodiversity (AFB, formerly ONEMA). This study is based upon works from COST Action CA15113 (SMIRES, Science and Management of Intermittent Rivers and Ephemeral Streams, www.smires.eu), supported by COST (European Cooperation in Science and Technology).

Edited by: Laurent Pfister

Reviewed by: Catherine Sefton and Anne Van Loon

\section{References}

Acuña, V., Datry, T., Marshall, J., Barceló, D., Dahm, C. N., Ginebreda, A., McGregor, G., Sabater, S., Tockner, K., and Palmer, M. A.: Why should we care about temporary waterways?, Science, 343, 1080-1081, 2014.

Acuña, V., Hunter, M., and Ruhí, A.: Managing temporary streams and rivers as unique rather than second-class ecosystems, Biol. Conserv., 211, 12-19, https://doi.org/10.1016/j.biocon.2016.12.025, 2017.

AFB (French Agency for Biodiversity): Observatoire National des Etiages (ONDE), available at: https://onde.eaufrance.fr (last access: 23 May 2018), 2012-2018.

Benda, L., Hassan, M. A., Church, M., and May, C. L.: Geomorphology Of Steepland Headwaters: The Transition From Hillslopes To Channels1, J. Am. Water Resour. As., 41, 835-851, 2005.

Benstead, J. P. and Leigh, D. S.: An expanded role for river networks, Nat. Geosci., 5, 678-679, 2012.

Boulton, A. J.: Conservation of ephemeral streams and their ecosystem services: what are we missing?: Editorial, Aquat. Conserv., 24, 733-738, https://doi.org/10.1002/aqc.2537, 2014.

Breiman, L.: Random forests, Mach. Learn., 45, 5-32, 2001.

Brugeron, A., Allier, D., and Klinka, T.: Approche exploratoire des liens entre référentiels hydrogéologique et hydrographique: Premières identifications des piézomètres potentiellement représentatifs d'une relation nappe/rivière et contribution à leur valorisation, Rapport final BRGM/RP-61047-FR, 241 pp., 2012.

Buytaert, W., Zulkafli, Z., Grainger, S., Acosta, L., Alemie, T. C., Bastiaensen, J., De Bièvre, B., Bhusal, J., Clark, J., Dewulf, A., Foggin, M., Hannah, D. M., Hergarten, C., Isaeva, A., Karpouzoglou, T., Pandeya, B., Paudel, D., Sharma, K., Steenhuis, T., Tilahun, S., Van Hecken, G., and Zhumanova, M.: Citizen science in hydrology and water resources: opportunities for knowledge generation, ecosystem service management, and sustainable development, Front. Earth Sci., 2, 1-21, https://doi.org/10.3389/feart.2014.00026, 2014.

Caillouet, L., Vidal, J.-P., Sauquet, E., Devers, A., and Graff, B.: Ensemble reconstruction of spatio-temporal extreme low-flow events in France since 1871, Hydrol. Earth Syst. Sci., 21, 2923 2951, https://doi.org/10.5194/hess-21-2923-2017, 2017.

Clarke, A., Mac Nally, R., Bond, N., and Lake, P. S.: Macroinvertebrate diversity in headwater streams: a review, Freshwater Biol., 53, 1707-1721, https://doi.org/10.1111/j.13652427.2008.02041.x, 2008.

Costigan, K. H., Jaeger, K. L., Goss, C. W., Fritz, K. M., and Goebel, P. C.: Understanding controls on flow permanence in intermittent rivers to aid ecological research: integrating 
meteorology, geology and land cover: Integrating Science to Understand Flow Intermittence, Ecohydrology, 9, 1141-1153, https://doi.org/10.1002/eco.1712, 2016.

Datry, T.: Benthic and hyporheic invertebrate assemblages along a flow intermittence gradient: effects of duration of dry events: River drying and temporary river invertebrates, Freshwater Biol., 57, 563-574, https://doi.org/10.1111/j.1365-2427.2011.02725.x, 2012.

Datry, T., Larned, S. T., Fritz, K. M., Bogan, M. T., Wood, P. J., Meyer, E. I., and Santos, A. N.: Broad-scale patterns of invertebrate richness and community composition in temporary rivers: effects of flow intermittence, Ecography, 37, 94-104, https://doi.org/10.1111/j.1600-0587.2013.00287.x, 2014a.

Datry, T., Larned, S. T., and Tockner, K.: Intermittent Rivers: A Challenge for Freshwater Ecology, BioScience, 64, 229-235, https://doi.org/10.1093/biosci/bit027, 2014b.

Datry, T., Pella, H., Leigh, C., Bonada, N., and Hugueny, B.: A landscape approach to advance intermittent river ecology, Freshwater Biol., 61, 1200-1213, https://doi.org/10.1111/fwb.12645, 2016a.

Datry, T., Fritz, K., and Leigh, C.: Challenges, developments and perspectives in intermittent river ecology, Freshwater Biol., 61, 1171-1180, https://doi.org/10.1111/fwb.12789, $2016 \mathrm{~b}$.

De Girolamo, A. M., Lo Porto, A., Pappagallo, G., Tzoraki, O., and Gallart, F.: The Hydrological Status Concept: Application at a Temporary River (Candelaro, Italy): Evaluating Hydrological Status In Temporary Rivers, River Res. Appl., 31, 892-903, https://doi.org/10.1002/rra.2786, 2015.

De Girolamo, A. M., Bouraoui, F., Buffagni, A., Pappagallo, G., and Lo Porto, A.: Hydrology under climate change in a temporary river system: Potential impact on water balance and flow regime, River Res. Appl., 33, 1219-1232, https://doi.org/10.1002/rra.3165, 2017a.

De Girolamo, A. M., Barca, E., Pappagallo, G., and Lo Porto, A.: Simulating ecologically relevant hydrological indicators in a temporary river system, Agr. Water Manage., 180, 194-204, https://doi.org/10.1016/j.agwat.2016.05.034, 2017 b.

Döll, P., and Schmied, H. M.: How is the impact of climate change on river flow regimes related to the impact on mean annual runoff? A global-scale analysis, Environ. Res. Lett., 7, 014037, https://doi.org/10.1088/1748-9326/7/1/014037, 2012.

Eng, K., Wolock, D. M., and Dettinger, M. D.: Sensitivity of Intermittent Streams to Climate Variations in the USA: Sensitivity of Intermittent Streams, River Res. Appl., 32, 885-895, https://doi.org/10.1002/rra.2939, 2016.

Finn, D. S., Bonada, N., Múrria, C., and Hughes, J. M.: Small but mighty: headwaters are vital to stream network biodiversity at two levels of organization, J. N. Am. Benthol. Soc., 30, 963-980, https://doi.org/10.1899/11-012.1, 2011.

Fritz, K. M., Hagenbuch, E., D’Amico, E., Reif, M., Wigington, P. J., Leibowitz, S. G., Comeleo, R. L., Ebersole, J. L., and Nadeau, T.-L.: Comparing the Extent and Permanence of Headwater Streams From Two Field Surveys to Values From Hydrographic Databases and Maps, J. Am. Water Resour. As., 49, 867882, https://doi.org/10.1111/jawr.12040, 2013.

Gallart, F., Prat, N., García-Roger, E. M., Latron, J., Rieradevall, M., Llorens, P., Barberá, G. G., Brito, D., De Girolamo, A. M., Lo Porto, A., Buffagni, A., Erba, S., Neves, R., Nikolaidis, N. P., Perrin, J. L., Querner, E. P., Quiñonero, J. M., Tournoud, M. G., Tzoraki, O., Skoulikidis, N., Gómez, R., Sánchez-Montoya, M.
M., and Froebrich, J.: A novel approach to analysing the regimes of temporary streams in relation to their controls on the composition and structure of aquatic biota, Hydrol. Earth Syst. Sci., 16, 3165-3182, https://doi.org/10.5194/hess-16-3165-2012, 2012.

Gallart, F., Llorens, P., Latron, J., Cid, N., Rieradevall, M., and Prat, N.: Validating alternative methodologies to estimate the regime of temporary rivers when flow data are unavailable, Sci. Total Environ., 565, 1001-1010, https://doi.org/10.1016/j.scitotenv.2016.05.116, 2016.

Garcia, C., Gibbins, C. N., Pardo, I., and Batalla, R. J.: Long term flow change threatens invertebrate diversity in temporary streams: Evidence from an island, Sci. Total Environ., 580, 1453-1459, https://doi.org/10.1016/j.scitotenv.2016.12.119, 2017a.

Garcia, C., Amengual, A., Homar, V., and Zamora, A.: Losing water in temporary streams on a Mediterranean island: Effects of climate and land-cover changes, Global Planet. Change, 148, 139152, https://doi.org/10.1016/j.gloplacha.2016.11.010, 2017b.

Gómez, R., Hurtado, I., Suárez, M. L., and Vidal-Abarca, M. R.: Ramblas in south-east Spain: threatened and valuable ecosystems, Aquat. Conserv., 15, 387-402, https://doi.org/10.1002/aqc.680, 2005.

González-Ferreras, A. M. and Barquín, J.: Mapping the temporary and perennial character of whole river networks: Mapping Flow Permanence In River Network, Water Resour. Res., 53, 6709_ 6724, https://doi.org/10.1002/2017WR020390, 2017.

Huxter, E. H. H. and van Meerveld, H. J.: Intermittent and Perennial Streamflow Regime Characteristics in the Okanagan, Can. Water Resour. J., 37, 391-414, https://doi.org/10.4296/cwrj2012-910, 2012.

IPCC.: Climate Change 2014: Synthesis Report. Contribution of Working Groups I, II and III to the Fifth Assessment Report of the Intergovernmental Panel on Climate Change, edited by: Core Writing Team, Pachauri, R. K., and Meyer, L. A., IPCC, Geneva, Switzerland, 151 pp., 2014.

Jaeger, K. L., Olden, J. D., and Pelland, N. A.: Climate change poised to threaten hydrologic connectivity and endemic fishes in dryland streams, P. Natl. Acad. Sci. USA, 111, 13894-13899, https://doi.org/10.1073/pnas.1320890111, 2014.

Kelso, J. E. and Entrekin, S. A.: Intermittent and perennial macroinvertebrate communities had similar richness but differed in species trait composition depending on flow duration, Hydrobiologia, 807, 189-206, https://doi.org/10.1007/s10750-017-3393y, 2018 .

Larned, S. T., Datry, T., Arscott, D. B., and Tockner, K.: Emerging concepts in temporary-river ecology, Freshwater Biol., 55, 717738, https://doi.org/10.1111/j.1365-2427.2009.02322.x, 2010.

Larue, J. P. and Giret A.: The drying up of streams in the Maine basin from 1989 to 1992, Norois, 192, 117-133, https://doi.org/10.4000/norois.944, 2004.

Lee, S.: Application of logistic regression model and its validation for landslide susceptibility mapping using GIS and remote sensing data, Int. J. Remote Sens., 26, 1477-1491, https://doi.org/10.1080/01431160412331331012, 2005.

Leigh, C. and Datry, T.: Drying as a primary hydrological determinant of biodiversity in river systems: a broad-scale analysis, Ecography, 40, 487-499, https://doi.org/10.1111/ecog.02230, 2017. 
Leigh, C., Boulton, A. J., Courtwright, J. L., Fritz, K., May, C. L., Walker, R. H., and Datry, T.: Ecological research and management of intermittent rivers: an historical review and future directions, Freshwater Biol., 61, 1181-1199, https://doi.org/10.1111/fwb.12646, 2016.

Leopold, L. B.: A View of the River, Harvard University Press, Cambridge, Massachusetts, USA, 1994.

Leopold, L. B., Wolman, M. G., and Miller, J. P.: Fluvial Processes in Geomorphology, Dover Publications, New York, USA, 1964.

Mérillon, Y.: Sécheresse, gestion de l'eau et pratiques agricoles, L'Information agricole, 649, 25-26, 1992.

Mérillon, Y. and Chaperon, P.: Drought in France in 1989, Houille Blanche, 325-340, https://doi.org/10.1051/lhb/1990025, 1990.

Meyer, J. L., Strayer, D. L., Wallace, J. B., Eggert, S. L., Helfman, G. S., and Leonard, N. E.: The Contribution of Headwater Streams to Biodiversity in River Networks1: The Contribution of Headwater Streams to Biodiversity in River Networks, J. Am. Water Resour. As., 43, 86-103, https://doi.org/10.1111/j.17521688.2007.00008.x, 2007.

Moreau, F.: Drought crisis management: Loire basin example, Houille Blanche, 4, 70-76, https://doi.org/10.1051/lhb:200404010, 2004.

Nadeau, T.-L. and Rains, M. C.: Hydrological Connectivity Between Headwater Streams and Downstream Waters: How Science Can Inform Policy1: Hydrological Connectivity Between Headwater Streams and Downstream Waters: How Science Can Inform Policy, J. Am. Water Resour. As., 43, 118-133, https://doi.org/10.1111/j.1752-1688.2007.00010.x, 2007.

Nash, J. E. and Sutcliffe, J. V.: River flow forecasting through conceptual models part I - A discussion of principles, J. Hydrol., 10, 282-290, https://doi.org/10.1016/0022-1694(70)90255-6, 1970.

Nowak, C. and Durozoi, B.: Observatoire National Des Etiages, Note technique, ONEMA, 2012.

Pella, H., Lejot, J., Lamouroux, N., and Snelder, T.: Le réseau hydrographique théorique (RHT) français et ses attributs environnementaux, Géomorphologie: relief, processus, environnement, 18, 317-336, 2012.

Pumo, D., Caracciolo, D., Viola, F., and Noto, L. V.: Climate change effects on the hydrological regime of small non-perennial river basins, Sci. Total Environ., 542, 76-92, https://doi.org/10.1016/j.scitotenv.2015.10.109, 2016.

Reynolds, L. V., Shafroth, P. B., and LeRoy Poff, N.: Modeled intermittency risk for small streams in the Upper Colorado River Basin under climate change, J. Hydrol., 523, 768-780, https://doi.org/10.1016/j.jhydrol.2015.02.025, 2015.

Sarremejane, R., Cañedo-Argüelles, M., Prat, N., Mykrä, H., Muotka, T., and Bonada, N.: Do metacommunities vary through time? Intermittent rivers as model systems, J. Biogeogr., 44, 2752-2763, https://doi.org/10.1111/jbi.13077, 2017.

Sauquet, E., Gottschalk, L., and Krasovskaia, I.: Estimating mean monthly runoff at ungauged locations: an application to France, Hydrol. Res., 39, 403, https://doi.org/10.2166/nh.2008.331, 2008.

Skoulikidis, N. T.: The environmental state of rivers in the Balkans-A review within the DPSIR framework, Sci. Total Environ., 407, 2501-2516, https://doi.org/10.1016/j.scitotenv.2009.01.026, 2009.
Skoulikidis, N. T., Vardakas, L., Karaouzas, I., Economou, A. N., Dimitriou, E., and Zogaris, S.: Assessing water stress in Mediterranean lotic systems: insights from an artificially intermittent river in Greece, Aquat. Sci., 73, 581-597, https://doi.org/10.1007/s00027-011-0228-1, 2011.

Skoulikidis, N. T., Vardakas, L., Amaxidis, Y., and Michalopoulos, P.: Biogeochemical processes controlling aquatic quality during drying and rewetting events in a Mediterranean non-perennial river reach, Sci. Total Environ., 575, 378-389, https://doi.org/10.1016/j.scitotenv.2016.10.015, 2017a.

Skoulikidis, N. T., Sabater, S., Datry, T., Morais, M. M., Buffagni, A., Dörflinger, G., Zogaris, S., del Mar Sánchez-Montoya, M., Bonada, N., Kalogianni, E., Rosado, J., Vardakas, L., De Girolamo, A. M., and Tockner, K.: Non-perennial Mediterranean rivers in Europe: Status, pressures, and challenges for research and management, Sci. Total Environ., 577, 1-18, https://doi.org/10.1016/j.scitotenv.2016.10.147, 2017b.

Snelder, T. H., Datry, T., Lamouroux, N., Larned, S. T., Sauquet, E., Pella, H., and Catalogne, C.: Regionalization of patterns of flow intermittence from gauging station records, Hydrol. Earth Syst. Sci., 17, 2685-2699, https://doi.org/10.5194/hess-17-2685-2013, 2013.

Storey, R. G. and Quinn, J. M.: Survival of aquatic invertebrates in dry bed sediments of intermittent streams: temperature tolerances and implications for riparian management, Freshw. Sci., 32, 250-266, https://doi.org/10.1899/12-008.1, 2013.

Stubbington, R. and Datry, T.: The macroinvertebrate seedbank promotes community persistence in temporary rivers across climate zones, Freshwater Biol., 58, 1202-1220, https://doi.org/10.1111/fwb.12121, 2013.

Turner, D. S. and Richter, H. E.: Wet/Dry Mapping: Using Citizen Scientists to Monitor the Extent of Perennial Surface Flow in Dryland Regions, Environ. Manage., 47, 497-505, https://doi.org/10.1007/s00267-010-9607-y, 2011.

Vadher, A. N., Millett, J., Stubbington, R., and Wood, P. J.: Drying duration and stream characteristics influence macroinvertebrate survivorship within the sediments of a temporary channel and exposed gravel bars of a connected perennial stream, Hydrobiologia, 814, 121-132, https://doi.org/10.1007/s10750-018-35449, 2018.

van Meerveld, H. J. I., Vis, M. J. P., and Seibert, J.: Information content of stream level class data for hydrological model calibration, Hydrol. Earth Syst. Sci., 21, 4895-4905, https://doi.org/10.5194/hess-21-4895-2017, 2017.

Vardakas, L., Kalogianni, E., Economou, A. N., Koutsikos, N., and Skoulikidis, N. T.: Mass mortalities and population recovery of an endemic fish assemblage in an intermittent river reach during drying and rewetting, Fund. Appl. Limnol., 190, 331-347, https://doi.org/10.1127/fal/2017/1056, 2017.

Wasson, J.-G., Chandesris, A., Pella, H., and Blanc, L.: Typology and reference conditions for surface water bodies in France: the hydro-ecoregion approach, TemaNord, 566, 37-41, 2002.

Woelfle-Erskine, C.: Collaborative Approaches to Flow Restoration in Intermittent Salmon-Bearing Streams: Salmon Creek, CA, USA, Water, 9, 217, https://doi.org/10.3390/w9030217, 2017. 